Check for updates

Cite this: Polym. Chem., 2018, 9, 1190

Received 9th November 2017 Accepted 6th February 2018

DOI: $10.1039 / c 7 p y 01883 e$

rsc.li/polymers

\section{A self-healable fluorescence active hydrogel based on ionic block copolymers prepared via ring opening polymerization and xanthate mediated RAFT polymerization $\uparrow$}

\author{
Sovan Lal Banerjee, ${ }^{a}$ Richard Hoskins, ${ }^{b}$ Thomas Swift, (D) ${ }^{b}$ Stephen Rimmer (D) *b and \\ Nikhil K. Singha (D) *a
}

In this work we report a facile method to prepare a fluorescence active self-healable hydrogel via incorporation of fluorescence responsive ionic block copolymers (BCPs). lonic block copolymers were prepared via a combined effect of ring opening polymerization (ROP) of $\varepsilon$-caprolactone and xanthate mediated reversible addition-fragmentation chain transfer (RAFT) polymerization. Here polycaprolactone (PCL) was modified with xanthate to prepare a PCL based macro-RAFT agent and then it was utilized to prepare block copolymers with cationic poly(2-(methacryloyloxy)ethyltrimethyl ammonium chloride) (PCL-b-PMTAC) and anionic poly(sodium 4-vinylbenzenesulfonate) (PCL-b-PSS). During the block formation, the cationic segments were randomly copolymerized with a trace amount of fluorescein $O$-acrylate (FA) (acceptor) whereas the anionic segments were randomly copolymerized with a trace amount of 9-anthryl methylmethacrylate (AMMA) (donor) to make both the segments fluorescent. The block copolymers form micelles in a DMF : water mixture (1:4 volume ratio). The ionic interaction of two BCPs was monitored via Förster resonance energy transfer (FRET) and zeta potential measurements. The oppositely charged BCPs were incorporated into a polyacrylamide (PAAm) based hydrogel that demonstrated self-healing behavior and is also highly fluorescent.

\section{Introduction}

After the invention of the first synthetic hydrogel in 1960 by Lim and Wichterle, ${ }^{1}$ they have been extensively used in different biomedical applications e.g. in tissue engineering, ${ }^{2}$ drug delivery, ${ }^{3}$ cell culture, ${ }^{4}$ and artificial organ development. ${ }^{5,6}$ The extensive use of different types of hydrogels in several potential fields is due to their high water content, elasticity, highly porous micro structure and 3D networks, which resemble biological tissues. ${ }^{7}$ Recently, fluorescence active hydrogels have been developed for use in several applications due to their optical response, ${ }^{8}$ which can be utilized in drug delivery systems, glucose sensors, ${ }^{9,10}$ thermoresponsive sensors, ${ }^{11}$ and insulin sensors, ${ }^{12}$ real time monitoring of the hydrogel behaviours like deformation, movement, and degradation, fluorescence guided monitoring of surgery etc. ${ }^{13-17}$ Many fluo-

${ }^{a}$ Rubber Technology Centre, Indian Institute of Technology, Kharagpur-721302, India. E-mail: nks@rtc.iitkgp.ernet.in

${ }^{b}$ School of Chemistry and Biosciences, University of Bradford, Bradford,

West Yorkshire, BD7 1DP, UK. E-mail: s.rimmer@bradford.ac.uk

$\dagger$ Electronic supplementary information (ESI) available: Characterization data (NMR, FTIR, Mass Spec, DLS) for compounds. See DOI: 10.1039/c7py01883e rescent materials such as conjugated conductive polymers, ${ }^{18,19}$ fluorescent nanoparticles (i.e. Ag NPs), ${ }^{20,21}$ fluorescent organic nanoparticles (FONs), ${ }^{22}$ carbon quantum dots (QDs), nanodots $^{23-25}$ and fluorescent dyes ${ }^{26}$ are used to incorporate luminescent properties into the polymeric hydrogel system. However, these materials suffer from several issues including: (i) high probability of aggregation of the nanodots or nanomaterials, resulting in self-quenching of fluorescence, (ii) the possibility that leaching of the nano materials can cause a toxic effect on the environment, and (iii) low structural stability in the presence of physical and chemical impacts. These issues could be overcome by employing a functional organic polymer consisting of covalently bound fluorophore units. ${ }^{27}$ Incorporation of covalently bound fluorescent labels has been shown to be a powerful way of studying both the internal conformational changes of stimuli responsive polymers ${ }^{28,29}$ and the complexation of multiple polymers in solution, ${ }^{30,31}$ and FRET analysis using two chromophores can provide additional information on both systems. ${ }^{32,33}$ Recently, Ma et al. reported a protein based hydrogel that can show green and red fluorescence but this system exhibits fluorescence only in the UV range, which hinders their in vivo application, and they are of low mechanical strength. ${ }^{17}$ Along with the fluorescence pro- 
perties it will be advantageous for a hydrogel to have self-healing behaviour. Self-healing is a biological phenomenon that provides a spontaneous recovery of the wound without any external stimuli. In a synthetic polymeric system self-healing can be of two types: (i) induced self-healing like $\mathrm{pH},{ }^{34}$ light, ${ }^{35}$ heat ${ }^{36}$ etc. and (ii) non-induced self-healing via the formation of ionic interaction, ${ }^{34} \mathrm{H}$-bonding, ${ }^{37} \pi-\pi$ stacking, ${ }^{38}$ metal co-ordination, ${ }^{39}$ etc. So far, reports on hydrogels having multifunctional ability like self-healing and fluorescent properties have been rare. So in this work, our aim is to synthesize tough, self-healable, fluorescence active and non-toxic multifunctional hydrogels. Labelling with fluorescent groups on the different polymers allowed us to use Förster resonance energy transfer (FRET) to study the interactions of the two oppositely charged blocks in aqueous media. The materials were also shown to be non-cytotoxic in cell culture.

In this case we first synthesized oppositely charged block copolymers using polycaprolactone-RAFT (PCL-RAFT) as a macro RAFT agent. PCL-RAFT was synthesized via ring opening polymerization (ROP) of $\varepsilon$-caprolactone (CL) using butanol as a ring opening initiator followed by the modification of the end group to incorporate xanthate functionality. This macro RAFT agent was utilized to prepare positively and negatively charged ionic block copolymers (BCPs). During the formation of ionic block copolymers a trace amount of fluorescein $O$-acrylate (FA) and 9-anthryl methylmethacrylate (AMMA) was copolymerized with cationic and anionic segments, respectively, to make them fluorescent. The interaction of the BCPs was monitored via Förster resonance energy transfer (FRET) and zeta potential measurement. These two fluorescence active BCPs were incorporated into poly(acrylamide) based hydrogels and the self-healing property of the hydrogel was monitored using mechanical analysis.

\section{Experimental}

\section{Materials}

$\varepsilon$-Caprolactone (CL) (Aldrich, St Louis, USA, 99\%) was dried over calcium hydride $\left(\mathrm{CaH}_{2}\right)$ for $48 \mathrm{~h}$ at room temperature and then distilled under reduced pressure. Triethylamine $\left(\mathrm{Et}_{3} \mathrm{~N}\right)$, 2-bromopropionyl bromide (97\%) (BiBr), stannous 2-ethylhexanoate $\left[\mathrm{Sn}(\mathrm{Oct})_{2}\right]$ (99\%), 2-(methacryloyloxy)ethyltrimethyl ammonium chloride (MTAC) solution $\left(80 \%\right.$ in $\left.\mathrm{H}_{2} \mathrm{O}\right)$ (monomer, purified by passing through a basic alumina column), 4-vinyl sodium styrenesulfonate (SS) (monomer), acrylamide (monomer), $N, N, N^{\prime}, N^{\prime}$-tetramethyl ethylenediamine (TEMED) (catalyst), ammonium persulfate (APS) (thermal initiator), 4,4'-azobis (4-cyanovaleric acid) (ABCVA) (thermal initiator), $N, N^{\prime}$-methylene bisacrylamide (MBA) (crosslinker), fluorescein $O$-acrylate (FA), $n$-butanol $(\mathrm{BuOH})$, carbon disulfide $\left(\mathrm{CS}_{2}\right)$, potassium hydroxide $(\mathrm{KOH})$, diethyl ether $\left(\mathrm{Et}_{2} \mathrm{O}\right)$, dicholoromethane $\left(\mathrm{CH}_{2} \mathrm{Cl}_{2}, \mathrm{DCM}\right)$, ethanol (EtOH), sodium hydrogen carbonate $\left(\mathrm{NaHCO}_{3}\right)$ and anhydrous magnesium sulfate $\left(\mathrm{MgSO}_{4}\right)$ were purchased from Sigma-Aldrich, USA. 9-Anthryl methylmethacrylate (AMMA) was purchased from TCI Chemicals, Japan. All the reagents for the in vitro MTT assay test were procured from Sigma Aldrich, USA. The NIH 3T3 fibroblast cell line was obtained from the National Centre for Cell Science, Pune, India.

\section{Methods}

Synthesis of PCL-OH. In a typical synthesis method $\varepsilon$-caprolactone (32 g, $280.35 \mathrm{mmol})$ was weighed out and butanol (365 $\mu \mathrm{l}, 0.295 \mathrm{~g}, 4 \mathrm{mmol}$ ) was added together with stannous 2-ethylhexanoate $\left(\mathrm{Sn}(\mathrm{Oct})_{2}\right)(256 \mu \mathrm{l})$ as a catalyst. The reaction vessel was sealed and purged with nitrogen and heated at $100{ }^{\circ} \mathrm{C}$ for $3 \mathrm{~h}$. On cooling, the polymer solidified and was redissolved in DCM and precipitated out in diethyl ether to produce a white powder (yield $=92 \%$ ). The molecular weight of the polymer was determined by ${ }^{1} \mathrm{H}$ NMR $\left(M_{\mathrm{n}} \mathrm{NMR}=7800\right.$ $\left.\mathrm{g} \cdot \mathrm{mol}^{-1}\right)$ and GPC $\left(M_{\mathrm{n} \mathrm{GPC}}=8500 \mathrm{~g} \mathrm{~mol}^{-1} ; \boxplus=1.30\right)$.

Synthesis of PCL-Br. Functionalization of PCL-OH to PCL-Br was performed according to Kuo et al. ${ }^{40}$ In a typical synthesis method $\mathrm{BiBr}(0.56 \mathrm{ml}, 2.59 \mathrm{mmol})$ was added dropwise to a continuous stirring mixture of PCL-OH (5 g, $0.647 \mathrm{mmol})$ and triethylamine $(0.9 \mathrm{ml}, 8.91 \mathrm{mmol})$ in dry DCM $(40 \mathrm{ml})$ at $0{ }^{\circ} \mathrm{C}$ for $1 \mathrm{~h}$. After complete addition of $\mathrm{BiBr}$, the whole reaction mixture was allowed to stir at room temperature for $48 \mathrm{~h}$. After that the reaction mixture was poured into $30 \mathrm{ml}$ of $5 \%$ $\mathrm{NaHCO}_{3}$ solution for neutralization of the resultant solution. This process was repeated 3 times and then the solution was washed with deionized water. The separation of the organic layer was carried out using a separating funnel and the resultant solution was dried over $\mathrm{MgSO}_{4}$. The solution was then filtered and precipitated in diethyl ether for purification. The resulting polymer was separated out via filtration and dried under vacuum for $24 \mathrm{~h}$.

Synthesis of potassium $O$-ethyl xanthate. $2.8 \mathrm{~g}(50 \mathrm{mmol})$ of $\mathrm{KOH}$ was stirred in $30 \mathrm{~mL}(0.645 \mathrm{~mol})$ of ethanol until a clear solution was obtained. Then, $10 \mathrm{~mL}(131 \mathrm{mmol})$ of $\mathrm{CS}_{2}$ was added slowly to the above solution under continuous stirring conditions and after that the reaction was carried out for $24 \mathrm{~h}$. The obtained reaction mixture was suspended in $300 \mathrm{~mL}$ diethyl ether and filtered. The solid product was washed three times with diethyl ether and dried under vacuum at room temperature for $24 \mathrm{~h}$. The purity of the obtained light yellow colored solid was analyzed using melting point determination $\left(210{ }^{\circ} \mathrm{C}\right) .{ }^{41}{ }^{1} \mathrm{H}$ NMR $\left(\mathrm{D}_{2} \mathrm{O}, \delta=1.27 \mathrm{ppm}\left(-\mathrm{CH}_{3}\right)\right.$ and $\delta=$ $\left.4.40 \mathrm{ppm}\left(-\mathrm{CH}_{2}-\right)\right),{ }^{13} \mathrm{C} \mathrm{NMR}\left(\mathrm{D}_{2} \mathrm{O}, \delta=13.65 \mathrm{ppm}\left(-\mathrm{CH}_{3}\right), \delta=\right.$ $70.17 \mathrm{ppm}\left(-\mathrm{CH}_{2}-\right)$ and $\delta=207.17 \mathrm{ppm}(\mathrm{C}=\mathrm{S})$ ) and mass spectra (the peak at 198.8 corresponds to the combined weight of the xanthate and potassium).

Synthesis of a PCL based macro RAFT agent. In a typical synthesis process, $2 \mathrm{~g}\left[0.256 \mathrm{mmol}\right.$, calculated on the basis of $M_{\mathrm{n}}$ NMR $\left.=7800 \mathrm{~g} \mathrm{~mol}^{-1}\right]$ of PCL-Br and $0.16 \mathrm{~g}$ of potassium $O$-ethyl xanthate $(0.998 \mathrm{mmol})$ were taken in a nitrogen purged round bottom flask and then degassed by three freeze-pump-thaw cycles. In another dried and nitrogen purged round bottom flask, $0.5 \mathrm{~mL}(8.5 \mathrm{mmol})$ of degassed pyridine was dissolved in $10 \mathrm{~mL}$ of degassed DCM under continuous stirring conditions. The resultant solution was added dropwise to the previously prepared reaction mixture with constant stirring at $0{ }^{\circ} \mathrm{C}$ and 
under a nitrogen atmosphere. After complete addition, the reaction mixture was allowed to stir at room temperature for $36 \mathrm{~h}$ and then diluted with $25 \mathrm{~mL}$ of DCM. The solution was washed consecutively with a saturated $\mathrm{NH}_{4} \mathrm{Cl}$ solution $(4 \times$ $25 \mathrm{~mL})$ and a saturated $\mathrm{NaHCO}_{3}$ solution $(4 \times 25 \mathrm{~mL})$, and distilled water $(4 \times 50 \mathrm{~mL})$. After that the resultant solution was separated out using a separating funnel and the obtained organic layer was dried over anhydrous $\mathrm{MgSO}_{4}$ and then filtered. The obtained solution was rotary evaporated to obtain the light yellow coloured PCL based Macro RAFT reagent.

Synthesis of the ionic block copolymer (BCP) using a PCL based macro-RAFT reagent. In a typical polymerization reaction, PCL-RAFT $\left(M_{\mathrm{n} \text { NMR }}=7800 \mathrm{~g} \mathrm{~mol}^{-1}\right)\left(0.3 \mathrm{~g}, 3.85 \times 10^{-2}\right.$ mmol) was dissolved in $3 \mathrm{ml}$ of DMF in a Schlenk tube. After that the monomer MTAC $(0.5 \mathrm{~g}, 2.425 \mathrm{mmol})$ and the initiator ABCVA $\left(0.0035 \mathrm{~g}, 3.005 \times 10^{-5} \mathrm{mmol}\right)$ were added into the reaction tube under an inert atmosphere. The whole reaction mixture was placed in an oil bath kept at $80{ }^{\circ} \mathrm{C}$ after purging $\mathrm{N}_{2}$ for $30 \mathrm{~min}$. After $24 \mathrm{~h}$, the obtained reaction mixture was placed in an ice bath and opened to air to stop the reaction. It was then precipitated in diethyl ether. After that, the obtained precipitate was again dissolved in DMF and dialysed in deionized water to remove the unreacted monomers and other reagents. A dialysis tube having a molecular weight cutoff of 3500 Da was used for dialysis. Finally, the BCP PCL- $b$-PMTAC was freeze-dried to obtain the final product. A similar procedure was adopted to obtain the PCL- $b$-PSS. ${ }^{1} \mathrm{H}$ NMR was utilized to determine the conversion of the polymerization reaction. To determine the interaction between the BCPs, the cationic block copolymer was copolymerized with FA $(0.5 \%$ of monomer amount, acceptor) (FAPCL- $b$-PMTAC) whereas the anionic block copolymer was copolymerized with 9-AMMA ( $0.5 \%$ of monomer amount, donor) (AMMAPCL- $b$-PSS).

Synthesis of an oppositely charged BCP micelle encapsulated polyacrylamide based hydrogel. In a typical synthesis process $10 \mathrm{~mL}$ (concentration $10 \mathrm{mg} \mathrm{mL}^{-1}$ ) of fluorescent cationic BCP micelle was mixed with $10 \mathrm{~mL}$ of fluorescent anionic BCP micelle under vigorous stirring conditions in a 3 neck round bottom flask and homogenized for $1 \mathrm{~h}$ under an inert atmosphere. After that, $7 \mathrm{~mL}$ of $20 \mathrm{wt} \%$ aqueous solution of acrylamide and $2 \mathrm{~mL}$ of $1 \mathrm{wt} \%$ aqueous solution of a crosslinker (MBA) and an initiator (APS) were added into the BCP solution sequentially under an inert atmosphere and allowed to stir for another $15 \mathrm{~min}$ for a proper homogenization. After that, $2 \mathrm{wt} \%$ aqueous solution of TEMED was injected into the mixture and stirred for $5 \mathrm{~min}$. Then the solution was transferred to a rectangular mould having dimensions of $40 \mathrm{~mm} \times$ $15 \mathrm{~mm} \times 3 \mathrm{~mm}(L \times W \times T)$ to obtain a perfectly shaped micelle containing fluorescent hydrogel. The mixture was allowed to gel for $24 \mathrm{~h}$ and then the rectangular shaped hydrogel was dipped in an ethanol-water mixture (1:4 volume ratio) for $16 \mathrm{~h}$ to make the hydrogel free from unreacted monomer and DMF. After that, the hydrogel was taken out of the solution and allowed to dry in a vacuum oven at $50{ }^{\circ} \mathrm{C}$ for $48 \mathrm{~h}$. A polyacrylamide based hydrogel having no BCPs and a hydrogel that consists of only cationic and anionic BCP micelles were
Table 1 Summary of hydrogel formation ${ }^{a, b, c, d, e}$

\begin{tabular}{lll}
\hline Batch & Cationic micelle & \\
\hline S1 & $2 \mathrm{ml}\left(\right.$ FAPCL $_{70}-b-$ PMTAC $\left._{48}\right)$ & $2 \mathrm{ml}\left(\right.$ AMMAPCL $_{70}-b-$ PSS $\left._{48}\right)$ \\
S2 & $2 \mathrm{ml}\left(\right.$ FAPCL $_{70}-b-$ PMTAC $\left._{97}\right)$ & $2 \mathrm{ml}\left(\right.$ AMMAPCL $\left._{70}-b-\mathrm{PSS}_{97}\right)$ \\
S3 & $2 \mathrm{ml}\left(\right.$ FAPCL $_{70}-b-$ PMTAC $\left._{48}\right)$ & $\mathrm{X}$ \\
S4 & $\mathrm{X}$ & $2 \mathrm{ml}\left(\right.$ AMMAPCL $_{70}-b-$ PSS $\left._{48}\right)$ \\
S5 & $2 \mathrm{ml}\left(\right.$ FAPCL $_{70}-b-$ PMTAC $\left._{97}\right)$ & $\mathrm{X}$ \\
S6 & $\mathrm{X}$ & $2 \mathrm{ml}\left(\right.$ AMMAPCL $_{70}-b-$ PSS $\left._{97}\right)$ \\
S7 & $\mathrm{X}$ & $\mathrm{X}$
\end{tabular}

${ }^{a}$ Amount of acrylamide $=4 \mathrm{~g}$ [total monomer concentration $\left.=20 \mathrm{wt} \%\right]$. ${ }^{b}$ Amount of MBA $=0.04 \mathrm{~g}$ [ $1 \mathrm{wt} \%$ of monomer amount]. ${ }^{c}$ Amount of APS $=0.04 \mathrm{~g}[1 \mathrm{wt} \%$ of monomer amount $] .{ }^{d}$ Amount of TEMED $=$ $0.08 \mathrm{~g}$ [2 wt\% of monomer amount]. ${ }^{e}$ Total batch volume $=20 \mathrm{ml}$. ${ }^{f}$ Conc. $=4 \mathrm{mg} \mathrm{ml}^{-1}$ in a $1: 4 \mathrm{DMF}:$ water mixture.

also prepared as a control sample. Details of the synthesis and formulation are summarized in Table 1.

\section{Characterisation}

Fourier transform infrared spectroscopy (FTIR) (PerkinElmer; model: Spectrum-2) was used to characterize the prepared sample. FTIR was operated in an ATR mode and at a scanning range of $500-4000 \mathrm{~cm}^{-1}$. Diffusion ordered NMR spectroscopy (DOSY) spectra and proton nuclear magnetic resonance $\left({ }^{1} \mathrm{H}\right.$ NMR) spectra were recorded on a Bruker Avance III $400 \mathrm{MHz}$ spectrometer at room temperature $\left(25 \pm 1{ }^{\circ} \mathrm{C}\right)$ using $\mathrm{D}_{2} \mathrm{O}$ as solvent.

In the case of DOSY analysis the gradient strength was gradually increased from $2 \%$ to $95 \%$ in a sequence of 16 steps. Bipolar rectangular gradients were maintained for a duration of $2 \mathrm{~ms}$ and the gradient recovery delay was $200 \mathrm{~ms}$. A maximum gradient strength of $0.535 \mathrm{~T} \mathrm{~m}^{-1}$ was used and the diffusion time was recorded between $0.5 \mathrm{~s}$ and $1.0 \mathrm{~s}$. The obtained spectrum was analysed using Topspin 2.1.6 software (Bruker). The molar mass and polydispersity $(\nexists)$ were determined using a gel permeation chromatography (GPC) (a Viscotek gel permeation chromatograph equipped with a VE 1122 solvent delivery system, using narrow dispersed polystyrene as a standard) analysis at room temperature. Tetrahydrofuran (THF) was used as an eluent at a flow rate of $1 \mathrm{~mL} \mathrm{~min}^{-1}$ and the data were analysed using OmniSEC 4.2 software. Field emission scanning electron microscopy (ZEISS, FESEM), operated at an accelerating voltage of $5 \mathrm{kV}$, was used to analyse the surface morphology of the prepared samples. To analyse the BCP micelle, the dilute solution $\left(1 \mathrm{mg} \mathrm{mL}^{-1}\right)$ (DMF $:$ water $=1: 4$ volume ratio) of BCPs was spin coated over a glass slide and allowed to dry at $40{ }^{\circ} \mathrm{C}$ inside a vacuum oven. To analyse the solid gel sample, the dried hydrogel was stuck over the tab using carbon adhesive tape. Before taking the images all the samples were gold coated. To examine the bulk morphology of the micelles, transmission electron microscopy (TEM) (JEOL, JEM-2000E7) was used. A dilute solution of micelles $\left(1 \mathrm{mg} \mathrm{mL} \mathrm{mL}^{-1}\right)$ (DMF $:$ water $=1: 4$ volume ratio) was drop cast over a carbon coated TEM grid of 300 mesh size and dried at ambient temperature before imaging. Atomic force 
microscopy (AFM) (Agilent 5500, USA) was also used to analyse the surface morphology of the micelle. Samples were prepared using the same process as that used for FESEM analysis. Tapping mode was used during AFM analysis. X-ray diffraction analysis (XRD) was carried out (PANalytical, Netherlands) using a copper X-ray source (1.549 $\AA$ ) with a standard angle of $0-80$ degrees $(2 \theta)$ and at a fixed scan rate of $1^{\circ}$ per minute. A dynamic light scattering (DLS) instrument (Malvern Nano ZS) was used to analyse the particle size of the BCPs. A scattering angle of $90^{\circ}$ and a $\mathrm{He}-\mathrm{Ne}(4 \mathrm{~mW}, \lambda=632.8 \mathrm{~nm})$ laser was used for this experiment. Water contact angles (WCA) of the synthesized polymers were obtained at ambient temperature using a Rame-Hart 260 F4 standard goniometer. A drop of liquid was placed onto the surface of the polymer film and the contact angles were measured within 5-10 s. Fluorescence measurements were carried out on a Horiba Fluoromax-4 Luminescence Spectrometer with a xenon discharge lamp and Monk-Gillieson type monochromators. The monochromator has a wavelength accuracy of $\pm 1.0 \mathrm{~nm}$. Emission and excitation slit widths were maintained at $1 \mathrm{~nm}$. The excitation scans were carried out by taking fixed excitation wavelengths of $365 \mathrm{~nm}$ and $475 \mathrm{~nm}$ for AMMA and FA tagged BCPs, respectively. For the FA labelled BCP, an emission wavelength of $480-800 \mathrm{~nm}$ and for the AMMA labelled BCP, an emission wavelength of 370-720 nm were fixed during the experiments. Tensile test analysis was carried out to confirm the self-healing ability of the hydrogel. Tensile testing was carried out in a Hounsfield H10KS tensile test machine by maintaining a crosshead speed of $10 \mathrm{~mm} \mathrm{~min}^{-1}$ and a load cell of $500 \mathrm{~N}$ at room temperature. During the tensile experiment the hydrogel samples were coated with silicon oil to prevent the elimination of entrapped water. The thermal properties of the block copolymer were analysed using differential scanning calorimetric analysis (DSC) (DSC 200 F3 instrument, Netzsch, Germany). The samples were heated from $-100{ }^{\circ} \mathrm{C}$ to $200{ }^{\circ} \mathrm{C}$ under a nitrogen atmosphere at a heating rate of $20^{\circ} \mathrm{C} \mathrm{min}^{-1}$. The temperature against the heat flow was recorded.

\section{Swelling study of the synthesized hydrogel}

The swelling ratio of the prepared hydrogel was determined gravimetrically. To study the swelling behaviour of the individual hydrogels, a preweighed amount of cylindrical shaped hydrogel sample was dipped into the PBS buffer solution having a $\mathrm{pH}$ of 7.4. After a certain time interval the swollen hydrogel was taken out of the solution and the surface water was removed by gently pressing the hydrogel with tissue paper before being weighed. The swelling ratio was calculated using the following formula:

$$
Q=\frac{W_{\text {swell }}-W_{\text {dry }}}{W_{\text {dry }}}
$$

where $W_{\text {swell }}$ and $W_{\text {dry }}$ are the swollen weight and dry weight of the hydrogel sample, respectively.

\section{Dynamic mechanical analysis (DMA)}

Creep study. Creep compliance measurements were carried out using a Dynamic Mechanical Analyzer (DMA) (Metravib $50 \mathrm{~N}$, France). The creep experiment was performed in the tension mode. For this experiment, the hydrogel samples (as prepared and self-healed) were subjected to a constant stress of $0.1 \mathrm{MPa}$. The resulting strain and its recovery were recorded at $25{ }^{\circ} \mathrm{C}$. The creep compliance $D(t)$ was calculated from the obtained stress and strain data using the following equation:

$$
\text { Creep }=D(t)=\frac{\varepsilon(t)}{\sigma_{0}}
$$

where $\sigma_{0}$ and $\varepsilon(t)$ are, respectively, the stress and strain on the samples.

Stress relaxation study. Stress relaxation experiments were also performed in the tension mode of a DMA instrument at $25{ }^{\circ} \mathrm{C}$. The samples were subjected to a constant strain of $0.02 \%$, and the resulting stress and its recovery were monitored. The as obtained stress and strain data were used to calculate the relaxation modulus $E(t)$ using the following equation:

$$
\text { Stress relaxation }=E(t)=\frac{\sigma_{\mathrm{t}}(t)}{\varepsilon_{0}}
$$

where $\sigma_{\mathrm{t}}(t)$ and $\varepsilon_{0}$ are, respectively, the stress and strain on the sample.

In vitro cell cytotoxicity assay. The NIH $3 \mathrm{~T} 3$ cell line was used to study the in vitro cell cytotoxicity assay. Here the MTT (3-(4,5-dimethylthiazol-2-yl)-2,5-diphenyltetrazolium bromide) colorimetric technique was adopted to monitor the change in metabolic activity of the fibroblast cell in the presence of the hydrogel. During the analysis a purple colored formazan salt was formed and by measuring the O.D. value at $590 \mathrm{~nm}$ one can identify the amount of cell viability. Under definite cell conditions the oxidoreductase enzymes reduced the MTT salt to generate formazan salt. Fibroblast cells at a concentration of $1 \times 10^{4}$ cells per well were seeded into a 96-well plate using $180 \mu \mathrm{l}$ of DMEM containing 10\% FBS and 1\% antibiotic. Then a PBS buffer containing hydrogel suspension was added to the medium and it was allowed to culture for $48 \mathrm{~h}$ under a humidified atmosphere in the presence of $5 \% \mathrm{CO}_{2}$. Cells in a growth medium containing no hydrogel were taken as a positive control. After that, the culture was washed with a PBS solution and an MTT solution having a concentration of $1 \mathrm{mg} \mathrm{mL}^{-1}$ was added before incubation for $4 \mathrm{~h}$ at $37^{\circ} \mathrm{C}$. After the incubation the supernatant was removed and insoluble formazan salt was dissolved in DMSO. The O.D. value of the purple solution was taken at a wavelength of $590 \mathrm{~nm}$. The relative cell viability was calculated using the following equation:

$$
\text { Cell viability }(\%)=\frac{\text { O.D.590(sample) }}{\text { O.D.590(control) }} \text {. }
$$

Statistical analysis. All the experiments on tensile testing and the in vitro cell cytotoxicity assay were carried out in triplicate and the reported values are the averages of all triplicate values \pm standard deviation. A Student's $t$-test was used to 
compare the statistical significance of the test samples against the control.

\section{Results and discussion}

Cationic (PCL- $b$-PMTAC) and anionic (PCL- $b$-PSS) amphiphilic block copolymers (BCPs) with different block lengths of cationic and anionic segments were prepared using PCL-RAFT as a macro RAFT agent. The PCL based macro RAFT agent was synthesized via a successive ROP of $\varepsilon$-caprolactone (CL) and xanthation of the prepared PCL unit. ROP of $\varepsilon$-caprolactone was carried out using butanol as a ring opening initiator and stannous 2-ethylhexanoate $\left[\mathrm{Sn}(\mathrm{Oct})_{2}\right]$ as a catalyst. The molecular weight of the PCL was determined from ${ }^{1} \mathrm{H}$ NMR $\left(M_{\mathrm{n}}=\right.$ $\left.7800 \mathrm{~g} \mathrm{~mol}^{-1}\right)$ and GPC analyses $\left(M_{\mathrm{n}}=8500 \mathrm{~g} \mathrm{~mol}^{-1}, D=1.30\right)$. During the molecular weight calculations by ${ }^{1} \mathrm{H} \mathrm{NMR}$, the
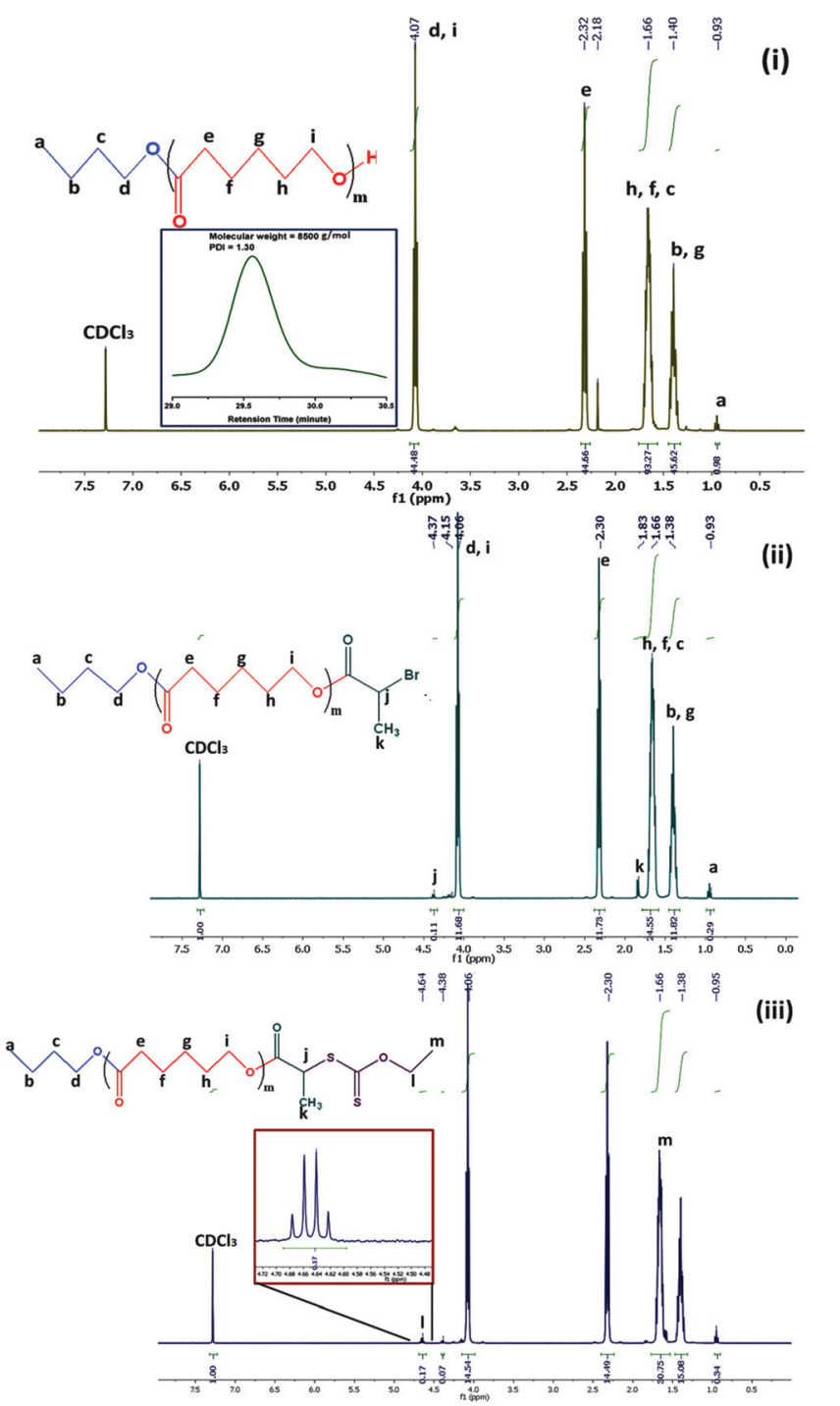

Fig. $1{ }^{1} \mathrm{H}$ NMR analysis of (i) $\mathrm{PCL}_{70}-\mathrm{OH}$ formed via $\mathrm{ROP}$, (ii) $\mathrm{PCL}_{70}-\mathrm{Br}$ and (iii) $\mathrm{PCL}_{70}$-RAFT. characteristic peaks of PCL at $\delta=0.98 \mathrm{ppm}$ (a, $-\mathrm{CH}_{3}$ proton) and at $\delta=2.4 \mathrm{ppm}$ (e, $-\mathrm{CO}-\mathrm{CH}_{2}$ ) were considered (Fig. 1(i)). The PCL was further utilized to prepare the macro-RAFT agent. To prepare the macro-RAFT agent, PCL was initially treated with $\mathrm{BiBr}$ and after that the obtained product was reacted with potassium $O$-ethyl xanthate. The successful bromination and xanthation of the PCL unit were verified by ${ }^{1} \mathrm{H}$ NMR analysis. For the PCL-Br the characteristic peak appeared at $\delta=1.9 \mathrm{ppm}$ $\left(\mathbf{k},-\mathrm{CH}-\mathrm{CH}_{3}\right)$ and at $\delta=4.4 \mathrm{ppm}(\mathbf{j},-\mathrm{CO}-\mathrm{CH})$ (Fig. 1(ii)). After xanthation a new resonance appeared at $\delta=4.7$ ppm (l, CS-O$\mathbf{C H}_{2}$ ) (Fig. 1(iii)). Scheme 1 summarizes the preparation of PCL-OH, PCL-Br and PCL based macro-RAFT. For the xanthation reaction $O$-ethyl xanthate was prepared using a previous report and the purity of the sample was checked by determining the melting point of the light yellow coloured solid (m.p. = $\left.210{ }^{\circ} \mathrm{C}\right),{ }^{1} \mathrm{H}$ NMR, ${ }^{13} \mathrm{C}$ NMR and mass spectral analyses. ${ }^{1} \mathrm{H}$ NMR (Fig. S1 $\dagger$ ) analysis of potassium $O$-ethyl xanthate provides characteristic peaks at $\delta=1.27 \mathrm{ppm}\left(-\mathrm{CH}_{3}\right)$ and at $\delta=$ $4.40 \mathrm{ppm}\left(-\mathrm{CH}_{2}-\right) .{ }^{13} \mathrm{C} \mathrm{NMR}$ analysis of potassium $\mathrm{O}$-ethyl xanthate provides characteristic peaks at $\delta=13.65 \mathrm{ppm}\left(-\mathrm{CH}_{3}\right)$, $\delta=70.17 \mathrm{ppm}\left(-\mathrm{CH}_{2}-\right)$ and $\delta=207.17 \mathrm{ppm}(\mathrm{C}=\mathrm{S})$. The purity of the prepared xanthate was also checked with mass spectral analysis. The major peaks obtained are 95, 198.8, 258.8, 518.8 and 678.8. The peak at 198.8 corresponds to the combined weight of xanthate and potassium. Higher peaks might appear due to the presence of dimers etc.

The macro RAFT agent was utilized to prepare the ionic block copolymers via xanthate mediated RAFT polymerization. Both cationic and anionic block copolymers of different block lengths were prepared. The formed BCPs were analysed using ${ }^{1} \mathrm{H}$ NMR analysis and differential scanning calorimetric (DSC) analysis. A summary of the BCP formation is presented in Table 2. The BCPs were prepared using DMF as a solvent and

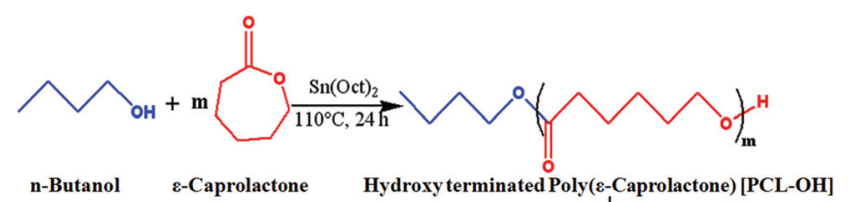

n-Butanol
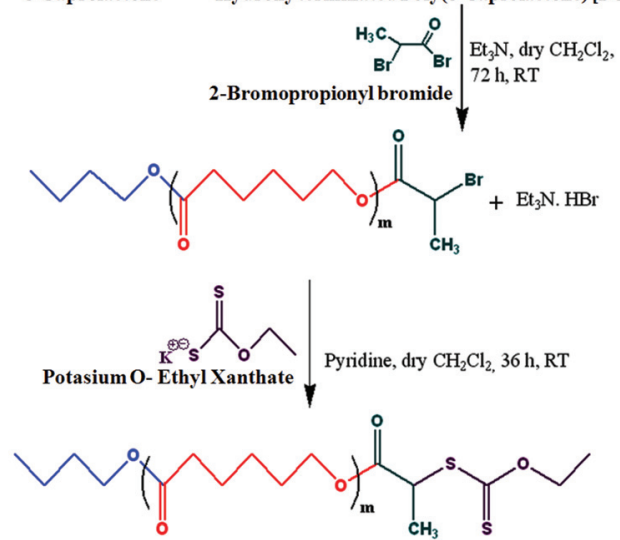

Xanthate Functionalized PCL [PCLRAFT]

Scheme 1 Synthesis of the PCL based macroinitiator and macro-RAFT. 
Table 2 Summary of the preparation of poly(caprolactone) (PCL) and its ionic BCP prepared via RAFT polymerization

\begin{tabular}{|c|c|c|c|c|c|c|}
\hline Sample & Composition & {$[\mathrm{M}]:$ CTA-RAFT : $[\mathrm{I}]$} & Conv. (\%) & Target MW $\left(\mathrm{g} \mathrm{mol}^{-1}\right)$ & $M_{\mathrm{n}}{ }^{a}\left(\mathrm{~g} \mathrm{~mol}^{-1}\right)$ & PCL (mol \%) \\
\hline PCLPM $_{1}$ & $\mathrm{PCL}_{70}-b-\mathrm{PMTAC}_{48}$ & $50: 1: 0.25$ & 97 & 17936 & 17559 & 59 \\
\hline $\mathrm{PCLPM}_{3}$ & $\mathrm{PCL}_{70}-b-\mathrm{PMTAC}_{194}$ & $200: 1: 0.25$ & 90 & 48158 & 46839 & 26 \\
\hline PCLPS $_{1}$ & $\mathrm{PCL}_{70}-b-\mathrm{PSS}_{48}$ & $50: 1: 0.25$ & 92 & 17888 & 17295 & 59 \\
\hline PCLPS $_{2}$ & $\mathrm{PCL}_{70}-b-\mathrm{PSS}_{97}$ & $100: 1: 0.25$ & 88 & 27982 & 26327 & 42 \\
\hline $\mathrm{PCLPS}_{3}$ & $\mathrm{PCL}_{70}-b-\mathrm{PSS}_{194}$ & $200: 1: 0.25$ & 89 & 47964 & 44528 & 26 \\
\hline
\end{tabular}

${ }^{a}$ Molecular weight was determined using ${ }^{1} \mathrm{H}$ NMR.

NMR was conducted using a mixture (1:1 volume ratio) of $\mathrm{D}_{2} \mathrm{O}$ and $\mathrm{d}_{8}$-THF. A schematic representation of the preparation method of fluorescent tagged BCPs is summarized in Scheme 2. The molecular weight of the 2nd ionic block copolymers was determined by ${ }^{1} \mathrm{H}$ NMR analysis. For $\mathrm{PCL}_{70}-b$ PMTAC $_{48}$ (Fig. 2(i)) the molecular weight of the PMTAC unit was calculated by considering the characteristic peak of PMTAC at $\delta=3.21 \mathrm{ppm}\left(\mathbf{n},-\mathrm{R}-\mathrm{N}\left(\mathrm{CH}_{3}\right)_{3}{ }^{+}\right)$and the characteristic peak of PCL at $\delta=2.4 \mathrm{ppm}\left(\mathbf{e},-\mathrm{CO}-\mathrm{CH}_{2}\right)$. Comparing the integral area of these two, the molecular weight of the ionic block was determined and it was $11270 \mathrm{~g} \mathrm{~mol}^{-1}$. The same method was applied for the anionic unit $\mathrm{PCL}_{70}-b$-PSS 48 (Fig. 2(ii)). By comparing the integral area of the characteristic peak of the PSS unit $(\delta=7.76 \mathrm{ppm}(\mathbf{0}, \mathrm{Ph}-\mathrm{CH}))$ and the characteristic peak of PCL at $\delta=2.4 \mathrm{ppm}\left(\mathbf{e},-\mathrm{CO}-\mathrm{CH}_{2}\right)$ the molecular weight of the PSS unit was $12350 \mathrm{~g} \mathrm{~mol}^{-1}$. To confirm the BCP formation, we carried out a DOSY analysis, which gives the shift of protons in the polymer solution and can be used to obtain hydrodynamic radii of polymer systems. ${ }^{42}$ This technique was used to demonstrate efficient grafting and block copolymerization by producing a $2 \mathrm{D}$ correlation diagram of the chemical shifts on the horizontal axis and the diffusion coefficient on the vertical axis. From the DOSY analysis (Fig. 2(iii)a-c) it was observed that the distribution of diffusion coefficients of BCPs of PCL with the cationic segments (Fig. 2(iii)b) and anionic segments (Fig. 2(iii)c) was substantially different from that of pristine PCL (Fig. 2(iii)a). This indicates that both blocks are attached and diffuse as a single distribution of chains.

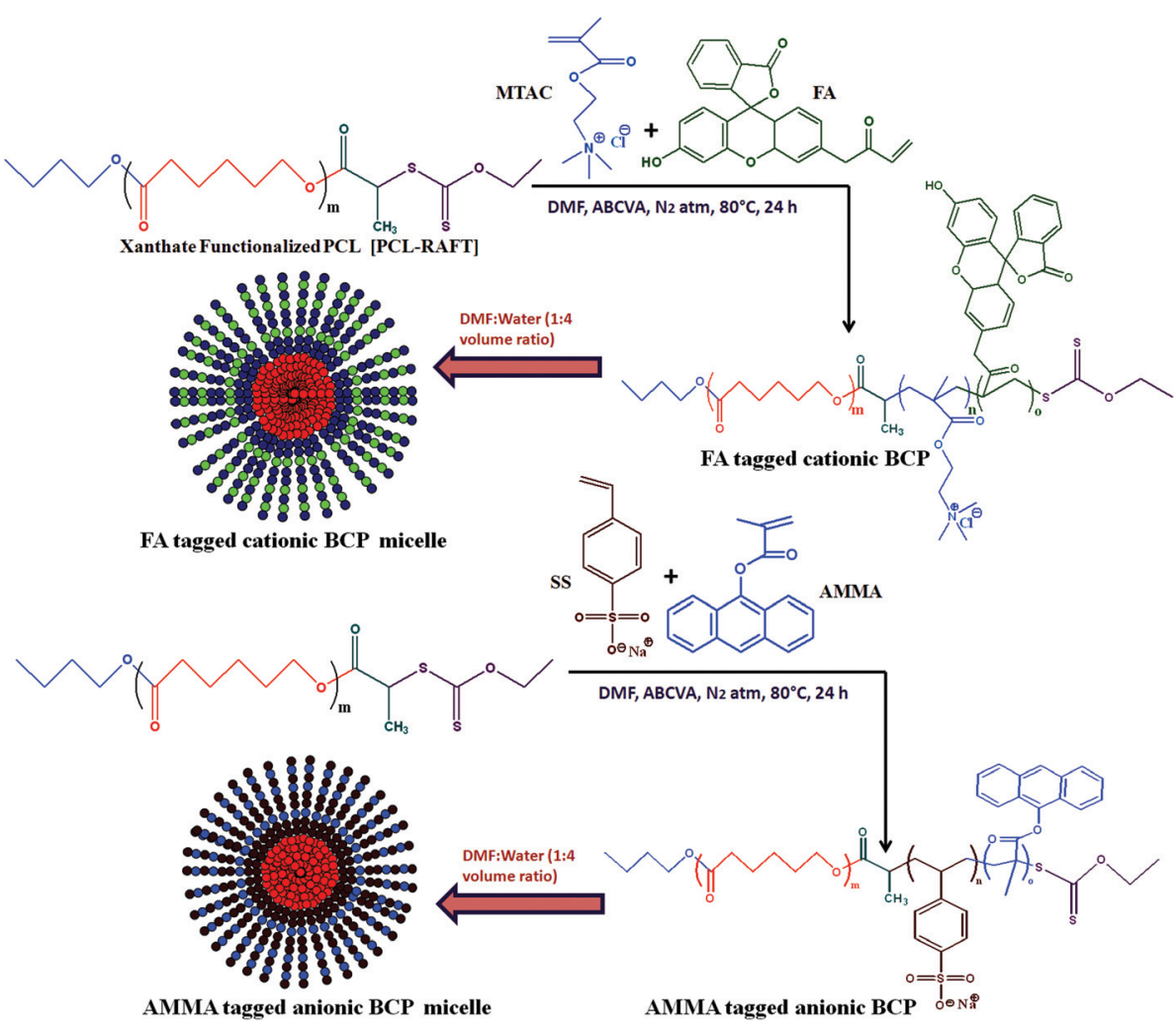

Scheme 2 Synthesis of amphiphilic cationic (PCL-b-PMTAC) and anionic (PCL-b-PSS) diblock copolymers via ROP and xanthate mediated RAFT polymerization and their self-assembly in a DMF : water mixture. 

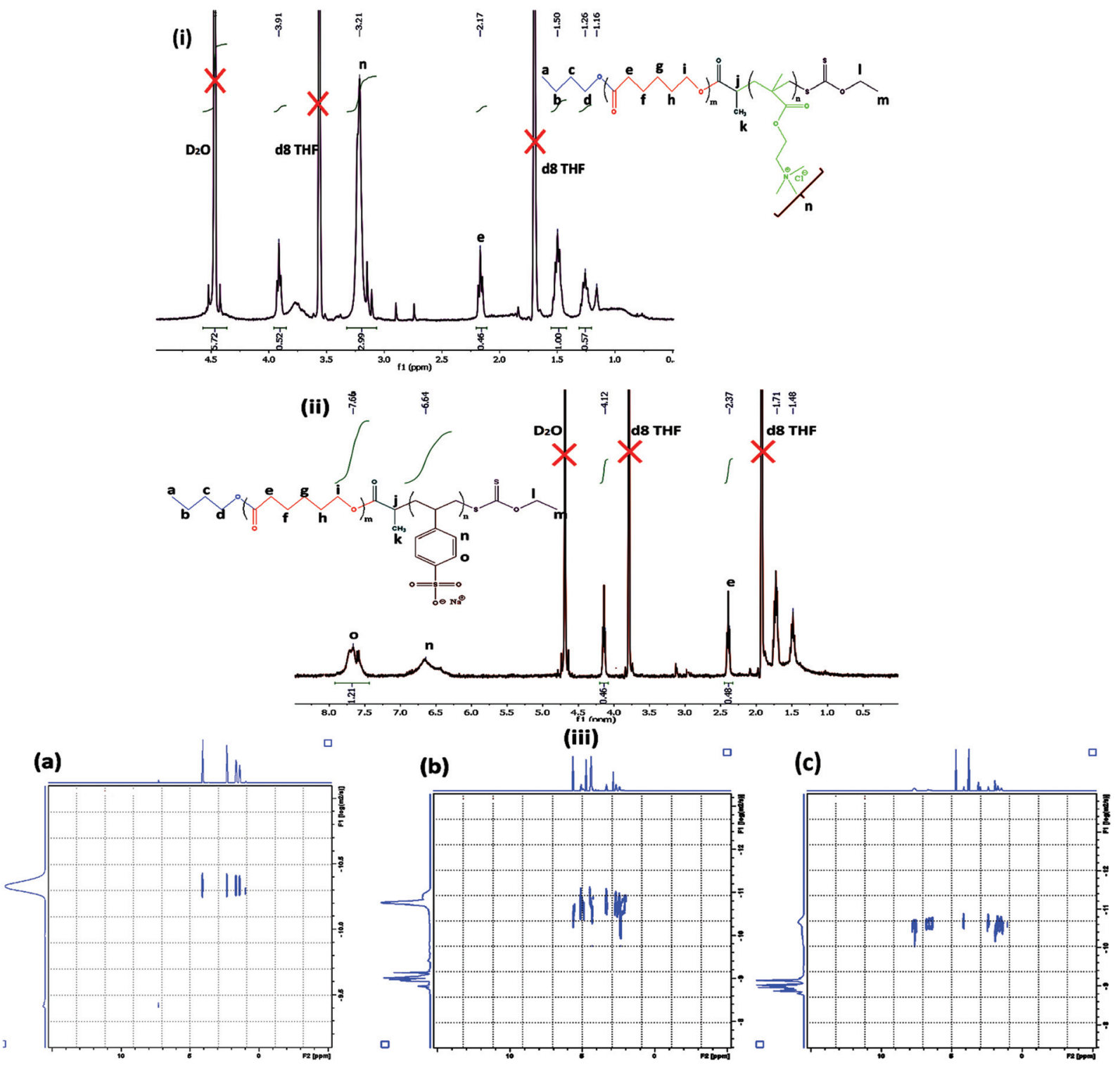

Fig. $2{ }^{1} \mathrm{H}$ NMR analysis of (i) $P C L_{70}-b-\mathrm{PMTAC}_{48}$ and (ii) $\mathrm{PCL}_{70}-b-\mathrm{PSS}_{48}$. (iii) DOSY analysis of (a) $P C L_{70}$, (b) $P C L_{70}-b-\mathrm{PMTAC}_{48}$ and (c) $P C L_{70}-b-P S S_{48}$.

The amphiphilic BCP was further analysed by FTIR analysis. From Fig. S4(a)† it was observed that pristine PCL had characteristic absorption bands at $1722 \mathrm{~cm}^{-1}$ and $1180 \mathrm{~cm}^{-1}$ due to the presence of $>\mathrm{C}=\mathrm{O}$ stretching and $\mathrm{C}-\mathrm{O}-\mathrm{C}$ stretching, respectively. In the case of cationic $\mathrm{BCP}$, along with the vibrational peaks of PCL new peaks appeared at $1491 \mathrm{~cm}^{-1}$ and $942 \mathrm{~cm}^{-1}$ which were due to the presence of $-\mathrm{CH}_{3}$ bending vibration of $\left[\mathrm{RN}\left(\mathrm{CH}_{3}\right)_{3}\right]^{+}$and $-\mathrm{CH}_{3}$ stretching vibration of $\left[\mathrm{RN}\left(\mathrm{CH}_{3}\right)_{3}\right]^{+}$, respectively.

The presence of the PSS unit in the BCP was confirmed by observing the presence of vibrational peaks at $1186 \mathrm{~cm}^{-1}$ and $1042 \mathrm{~cm}^{-1}$, which are due to anti-symmetric and symmetric vibrational peaks of the $\mathrm{SO}_{3}{ }^{-}$group.

The change in crystallinity of the PCL unit after the formation of the cationic and anionic BCPs was monitored through XRD analysis. The PCL homopolymer shows sharp crystalline peaks at $21^{\circ}$ and $24^{\circ}$, which are due to scattering from the [110] and [200] crystallographic planes. Fig. S4(b) $\dagger$ shows that upon the formation of BCPs the crystalline component of the PCL was reduced and the peak becomes broader, indicating the introduction of amorphous characteristics in the $\mathrm{BCP}^{43}$

\section{Self-assembly of the ionic amphiphilic BCPs in a water : DMF mixture}

It is widely reported that BCPs with chemically distinct and immiscible segments combine to form immiscible selfassembled structures when they are dissolved in a solvent with different solubility for different blocks. The morphology of self-assembly depends on a number of factors. ${ }^{44}$ When the soluble block has dominancy over the insoluble block it forms a spherical core shell type of structure. In our case the PCL 
based amphiphilic ionic BCPs form a spherical morphology in a DMF : water mixture (1:4 volume ratio). To prepare a coreshell type morphology, initially the cationic and anionic BCPs were dissolved separately in DMF, which is a thermodynamically favourable solvent for both of the segments. After homogenization, the mentioned amount of water was added dropwise to the solution with continuous stirring; it was observed that in both cases the opaque BCP dispersion turned relatively transparent, indicating the formation of stable micelles. The formation of stable micellar structures depends on two factors: (i) the formation of stable aggregates by the insoluble part of the BCP and (ii) the repulsive and attractive forces present between the nearby polymer segments and between the polymer-solvent, respectively. ${ }^{45}$ The morphology of the formed "core-shell" BCPs was observed using different microscopic techniques like FESEM, HRTEM and AFM analyses and also by a DLS study. Light scattering analysis (Fig. S5(a)†) was utilized to monitor the hydrodynamic radius provided by different BCPs having different block lengths of cationic and anionic segments. It was observed that with an increase in the block length of the cationic segment from $\mathrm{PCL}_{70}-b$ - $\mathrm{PMTAC}_{48}$ to $\mathrm{PCL}_{70}-b$ - $\mathrm{PMTAC}_{97}$ to $\mathrm{PCL}_{70}-b$ - $\mathrm{PMTAC}_{194}$, the hydrodynamic radius also increased gradually from $370 \pm$ $5 \mathrm{~nm}$ (poly dispersity index $(\mathrm{PDI})=0.247)$ to $440 \pm 5 \mathrm{~nm}(\mathrm{PDI}=$ 0.348). The same phenomenon was also observed in the case of the anionic segment; when the anionic block length was varied from $\mathrm{PCL}_{70}-b$ - $\mathrm{PSS}_{48}$ to $\mathrm{PCL}_{70}-b-\mathrm{PSS}_{97}$ to $\mathrm{PCL}_{70}-b-\mathrm{PSS}_{194}$, the hydrodynamic radius gradually increased from $325 \pm 4 \mathrm{~nm}$ $(\mathrm{PDI}=0.174)$ to $348 \pm 5 \mathrm{~nm}(\mathrm{PDI}=0.298)$. This might be due to the greater solvation of the hydrophilic segments.
Interestingly, it was observed that very high block lengths of cationic and anionic segments hinder the formation of micellar structures and no particle diameter was found. During the dynamic light scattering measurement a solution concentration of $1 \mathrm{mg} \mathrm{mL}^{-1}$ was maintained. From the water contact angle (WCA) analysis (Fig. S5(b)†), it was observed that the formation of the BCP results in a decrease in the WCA. For pristine PCL, the WCA value was $72^{\circ}$ whereas the cationic and anionic BCPs showed a WCA value of $32^{\circ}$ and $36^{\circ}$, respectively. The formation of ionic BCP aggregates further reduced the WCA value and it was $20^{\circ}$, which indicates hydrophilicity of the assembled complex.

For all microscopic analyses, BCPs with poly(ionic) segments of $M_{\mathrm{n}}=10 \mathrm{~kg} \mathrm{~mol}{ }^{-1}$ were considered as they have a lower micellar size. Fig. 3(i) summarizes the microscopic images obtained in FESEM analysis. From the figure it was observed that both the cationic (Fig. 3(i)a) and the anionic BCPs (Fig. 3(i)b) formed spherical micelles. When both the BCPs were mixed together they formed an aggregate, as observed in the FESEM image (Fig. 3(i)c). A similar observation was also obtained in HRTEM analysis. From the HRTEM study it was observed that the PCL based BCPs formed a spherical "core-shell" morphology, whereas the PCL segment formed the dark core part and the lighter dark corona was formed by the PMTAC (Fig. 3(ii)a) and PSS (Fig. 3(ii)b) units in the cationic and anionic BCPs, respectively. The size obtained from the HRTEM analysis for both of the BCPs is in the range of $200 \pm 10 \mathrm{~nm}$. It was observed that when both of the oppositely charged BCPs were mixed at a lower concentration the obtained HRTEM image showed similarity to a worm like mor-
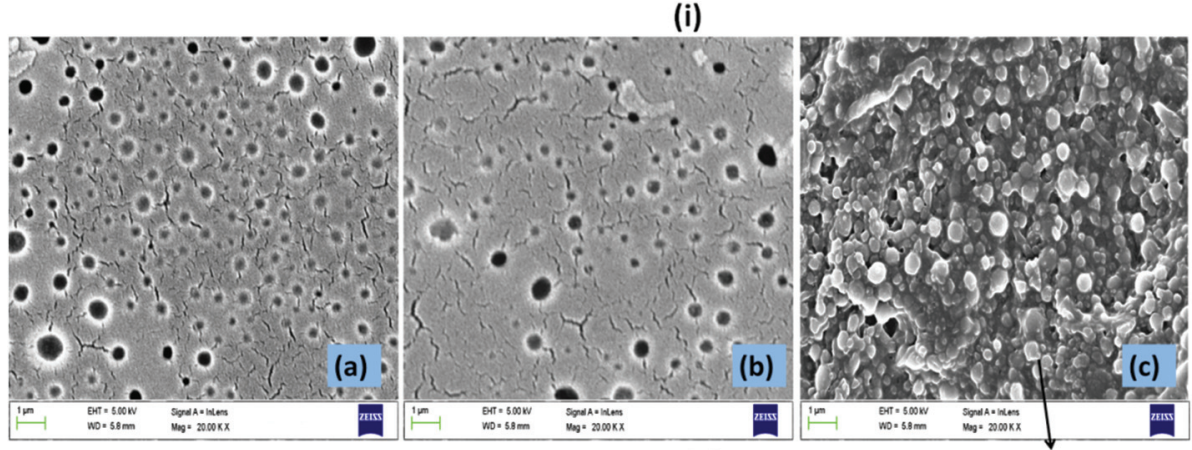

(ii)
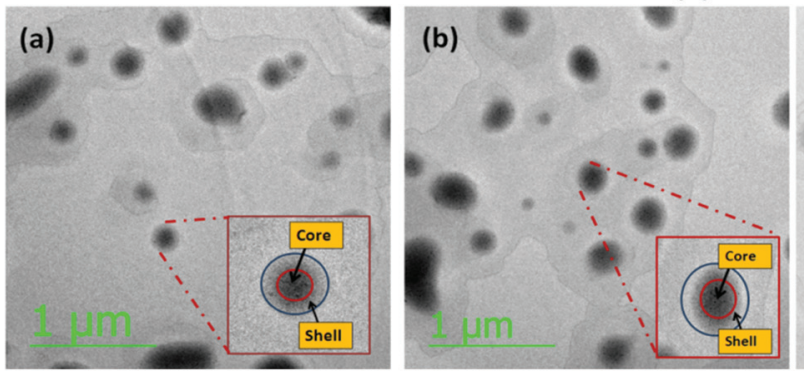

lonically interacted micelle

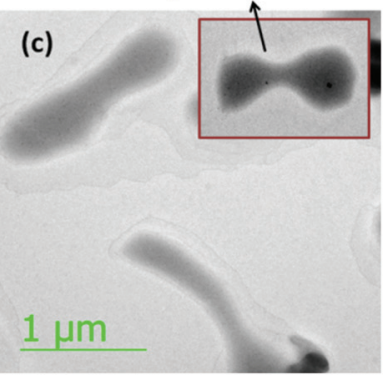

Fig. 3 (i) FESEM and (ii) TEM images of the formed (a) $\mathrm{PCL}_{70}-b-\mathrm{PMTAC}_{48}$ micelle, (b) $\mathrm{PCL}_{70}-b-\mathrm{PSS}_{48}$ micelle, and (c) ionically interacted $\mathrm{BCPs}$ in aqueous solution (picture taken after drying the solution). 


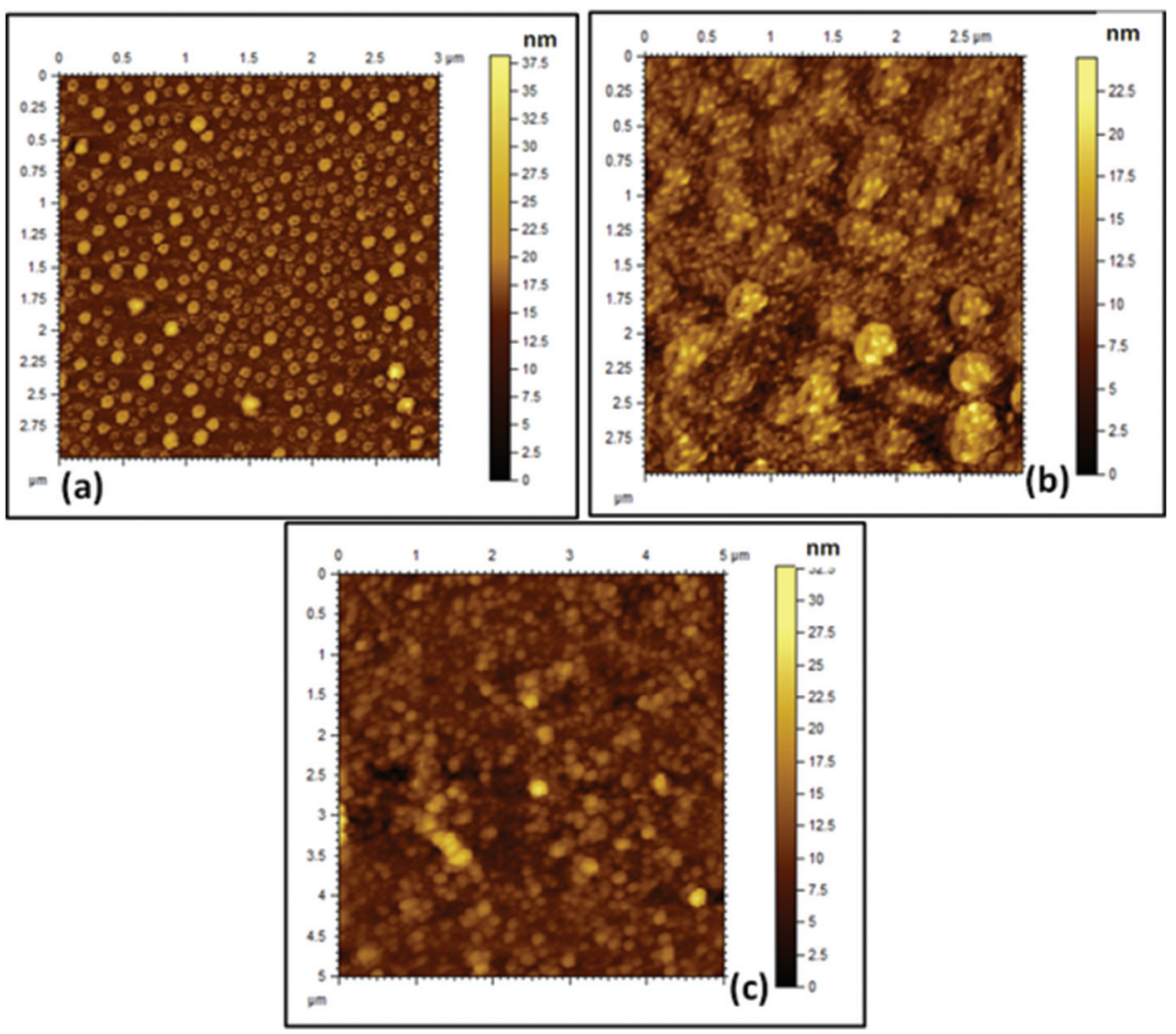

Fig. 4 AFM images of the formed (a) PCL70-b-PMTAC48 micelle, (b) PCL70-b-PSS48 micelle, and (c) ionically interacted BCP micelle in aqueous solution (picture taken after drying the solvent).

phology. This might be due to the formation of a continuous structure by the ionic interaction between the cationic and the anionic BCPs.

The obtained AFM (Fig. 4) images also corroborate the results obtained from FESEM and HRTEM analyses. From the AFM image it was observed that both the cationic (Fig. 4a) and anionic (Fig. 4b) segments exhibit a spherical morphology having a "core-shell" structure. The average size obtained for both of the BCPs was in the range of $180 \pm 10 \mathrm{~nm}$. A mixture of the two polyelectrolyte BCPs results in aggregated structures (Fig. 4c) as obtained in FESEM and HRTEM.

The interaction between the oppositely charged BCPs was further confirmed through additional fluorescence spectroscopy and zeta potential analyses.

To measure the fluorescence activity of the positively and negatively charged BCPs, during the block copolymerization of cationic and anionic segments with the PCL unit a small amount $(0.5 \%$ of the monomer) of fluorescein $O$-acrylate (FA) (acceptor) and 9-anthryl methylmethacrylate (AMMA) (donor) was copolymerized with PMTAC and PSS units, respectively. Fluorescence excitation scans were carried out by sample excitation at $365 \mathrm{~nm}$ and $475 \mathrm{~nm}$ for AMMA and FA tagged BCPs, respectively, in a dilute solution. Fig. $5 \mathrm{a}$ and $\mathrm{b}$ show the fluorescence emission graph of FA labelled $\mathrm{PCL}_{70}-b$ - $\mathrm{PMTAC}_{48}$ and AMMA tagged $\mathrm{PCL}_{70}-b$-PSS ${ }_{48}$, respectively. Additional measurements were carried out and energy transfer between the two chromophores via a FRET mechanism was observed when the cationic and anionic polymers were mixed. In this study, $200 \mu \mathrm{L}$ of an AMMA tagged $\mathrm{PCL}_{70}-b-\mathrm{PSS}_{48}$ solution $\left(\right.$ DMF $:$ water $=1: 4$ volume ratio) $\left(\right.$ conc. $=10 \mathrm{mg} \mathrm{mL} L^{-1}$ ) was mixed with different volumes of FA tagged $\mathrm{PCL}_{70}-b-\mathrm{PMTAC}_{48}$ solution and the total volume of the solution was maintained at $1 \mathrm{~mL}$. As a result of the increasing concentration of FA (acceptor), the intensity of the AMMA (donor) decreased as shown in Fig. 5c. This demonstrates the increasing interaction between cationic and anionic segments bringing the two labels together. However, after a certain amount of acceptor containing cationic polymer, equilibrium was achieved and the $I_{\mathrm{A}} / I_{\mathrm{D}}$ value stabilized, indicating a FRET neutralization point ( $300 \mu \mathrm{L}$ of cationic BCP added to $200 \mu \mathrm{L}$ of anionic BCP). After this value no additional FRET occurred with increasing cationic polymer addition. Fig. $5 \mathrm{~g}$ presents a schematic of the FRET between cationic and anionic BCP. As FRET will only occur over a limited spatial distance this measurement indicates the critical ratio of anionic and cationic polymers required to achieve full complexation between the two polymers, and further increases in concentration do not lead to further supramolecular assembly.

The interaction of the oppositely charged micelles was also monitored by studying the variation of the zeta potential value upon the addition of one component (FA tagged $\mathrm{PCL}_{70}-b$ $\mathrm{PMTAC}_{48}$ solution, positively charged) into another (AMMA 

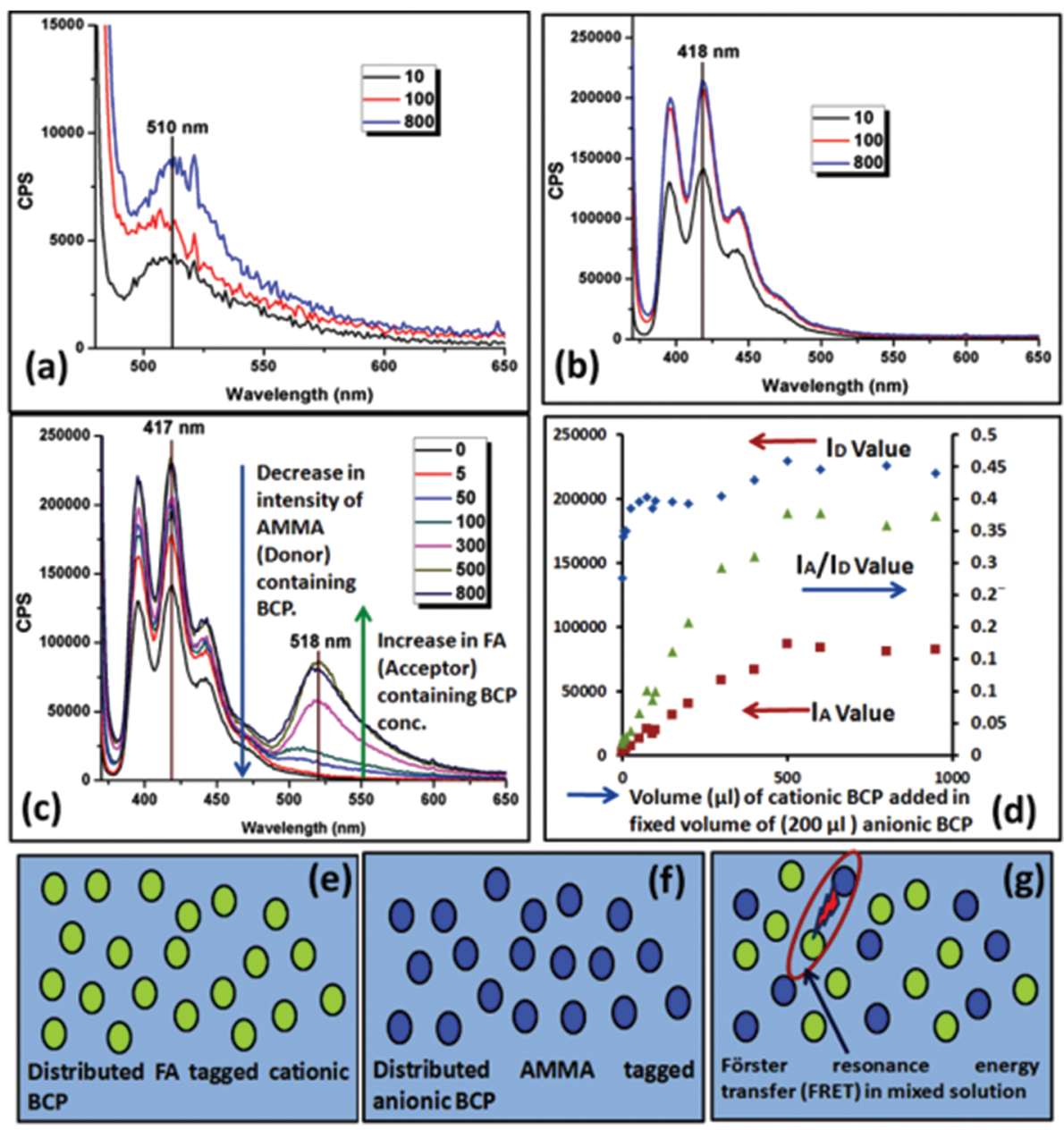

Fig. 5 Fluorescence spectroscopic results of (a) the $\mathrm{PCL}_{70}-b-\mathrm{PMTAC}_{48}$ micelle, and (b) the $\mathrm{PCL}_{70}-b-\mathrm{PSS} 48$ micelle; (c) the results of FRET energy transfer during the mixing of the cationic and anionic BCPs; (d) a correlation plot of the FRET when cationic and anionic micelle were mixed together and the respective IA/ID plot. Schematic representation of the solvent distributed (e) cationic BCP and ( $f$ ) anionic BCP and ( $g$ ) FRET between cationic and anionic BCPs.

tagged $\mathrm{PCL}_{70}-b$-PSS 48 solution, negatively charged). The obtained result is summarized in Table 3. As observed from the result a gradual increase in the zeta potential occurs upon addition of the positively charged micellar solution into the negatively charged micellar solution.

The concentration of the prepared $\mathrm{FAPCL}_{70}-b$ - $\mathrm{PMTAC}_{48}$ and

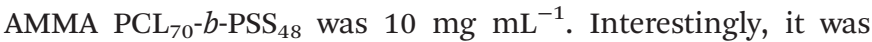
observed that a transition point appeared during the zeta potential titration when the system suddenly showed a high positively charge value from a high negatively charge value. The mid-point of these two transitions designates the charge neutrality point. The conditions under which charge neutrality is achieved are highlighted in Table 3.

\section{Thermal analysis}

Thermal analyses of the PCL homopolymer and the PCL based ionic block copolymers were carried out to determine the change in thermal behaviour of the PCL upon block copolymerization and also to determine the $T_{\mathrm{g}}$ of the segments. It is well known that PCL is a crystalline polymer, so a strong melting point peak appeared at $60{ }^{\circ} \mathrm{C}$ as shown in Fig. 6a. After copolymerization it was observed that the peak intensity was drastically reduced due to the disruption of the crystalline nature of the PCL unit (Fig. 6b). ${ }^{46}$ The $T_{\mathrm{g}}$ of the cationic and the anionic segment were determined using the DSC thermogram. Fig. $6 \mathrm{c}$ and $\mathrm{d}$ show that the $T_{\mathrm{g}}$ of the PMTAC and the PSS units are $35^{\circ} \mathrm{C}$ and $92^{\circ} \mathrm{C}$, respectively.

Preparation of a fluorescence active hydrogel and its swelling properties

As discussed in the Experimental section, both the BCP micelles (cationic and anionic) prepared in a $1: 4$ volume ratio of a DMF : water mixture were incorporated into the poly(acrylamide) based hydrogel. The hydrogel was prepared using acrylamide as a monomer, MBA as a crosslinker and APS as a thermal initiator. TEMED was used as a room temperature gelator. As shown in Fig. 7(i), the cationic (Fig. 7(i)b) and the anionic (Fig. 7(i)c) BCPs were fluorescent and they provided a 
Table 3 Results of zeta potential analysis and FRET analysis when two oppositely charged micelles were mixed together

\begin{tabular}{|c|c|c|c|}
\hline $\begin{array}{l}\text { Amount of } \\
\text { water : DMF } \\
\text { mixture }(4: 1 \\
\text { volume ratio })(\mu \mathrm{l})\end{array}$ & $\begin{array}{l}\text { Amount of AMMA } \\
\text { tagged PCL } \text { PC }_{70}-b \\
\text { PMTAC }_{48} \\
\text { solution }^{a, b}(\mu \mathrm{L})\end{array}$ & $\begin{array}{l}\text { Zeta } \\
\text { potential } \\
(\mathrm{mV})\end{array}$ & $\begin{array}{l}I_{\mathrm{A}} / I_{\mathrm{D}} \text { value } \\
\text { acquired from } \\
\text { FRET analysis }\end{array}$ \\
\hline 798 & 2 & $-44.3 \pm 2.0$ & 0.0283 \\
\hline 795 & 5 & $-39.1 \pm 2.0$ & 0.0246 \\
\hline 790 & 10 & $-37.2 \pm 1.0$ & 0.0293 \\
\hline 775 & 25 & $-34.5 \pm 2.0$ & 0.0382 \\
\hline 750 & 50 & $-31.9 \pm 2.0$ & 0.0666 \\
\hline 720 & 75 & $-31.5 \pm 1.0$ & 0.1012 \\
\hline 710 & 90 & $-30.8 \pm 1.2$ & 0.0865 \\
\hline 700 & 100 & $-30.1 \pm 1.0$ & 0.1006 \\
\hline 650 & 150 & $-28.7 \pm 2.0$ & 0.1617 \\
\hline 600 & 200 & $+1.56 \pm 2.0$ & 0.2076 \\
\hline 500 & 300 & $+17.2 \pm 1.0$ & 0.2926 \\
\hline 400 & 400 & $+19.2 \pm 1.0$ & 0.3104 \\
\hline 300 & 500 & $+22.5 \pm 2.0$ & 0.3781 \\
\hline 200 & 600 & $+27.4 \pm 2.0$ & 0.3782 \\
\hline 0 & 800 & $+32.5 \pm 3.0$ & 0.3597 \\
\hline 0 & 950 & $+41.2 \pm 3.0$ & 0.3736 \\
\hline
\end{tabular}

${ }^{a}$ Amount of AMMA tagged $\mathrm{PCL}_{70}-b-\mathrm{PSS}_{48}$ solution $=200 \mu \mathrm{l} .{ }^{b}$ Base solvent was prepared by mixing water and DMF in $4: 1$ volume ratio.

yellow and a blue colour emission under fluorescent light, respectively. A mixture of DMF : water $(1: 4$ volume ratio) was used as a control sample under fluorescence (Fig. 7(i)a). When both the micelles were mixed at an almost equal charge ratio, it resulted in a mixed colour where the intensity of the yellow and the blue colours was quenched to some extent. This mixture was further used to prepare the fluorescence active hydrogel. Fig. 7(i)e and f provide the images of the fluorescent hydrogel under visible and fluorescent light. To measure the extent of swelling of the synthesized hydrogel at $\mathrm{pH}=7.4$ buffer solution, each of the hydrogels was immersed in the buffer solution separately and after a predetermined time interval the swelling ratio was measured gravimetrically. It was observed that with an increase in the block length of the incorporated BCP the extent of swelling was reduced. As observed in Fig. 7(ii), the non-modified hydrogel (no BCP incorporation) showed $(1300 \pm 26) \%$ swelling whereas the hydrogel with FAPCL $_{70}-b-\mathrm{PMTAC}_{48}+$ AMMAPCL $_{70}-b-\mathrm{PSS}_{48}$ showed $(1200 \pm$ $30) \%$ swelling compared to the FAPCL $_{70}-b-\mathrm{PMTAC}_{97}+$ AMMAPCL $_{70}-b$ - PSS $_{97}$ incorporated hydrogel $((1000 \pm 22) \%$ swelling). The deviation in swelling can be explained by considering the ionic interlocking of the BCPs inside the hydrogel. The non-modified hydrogel has no such ionic interaction in the bulk so the free volume is comparatively higher compared to the ionic BCP incorporated hydrogel, which results in a higher degree of swelling. In the case of the FAPCL $_{70}-b$ $\mathrm{PMTAC}_{48}+\mathrm{AMMAPCL}_{70}-b-\mathrm{PSS}_{48}$ containing hydrogel the ionic block length is comparatively low compared to $\mathrm{FAPCL}_{70}-b$ PMTAC $_{97}+$ AMMAPCL $_{70}-b-\mathrm{PSS}_{97}$. It provides a higher degree of swelling as the extent of physical crosslinking (ionic interaction between two oppositely charged BCPs) is less. As a
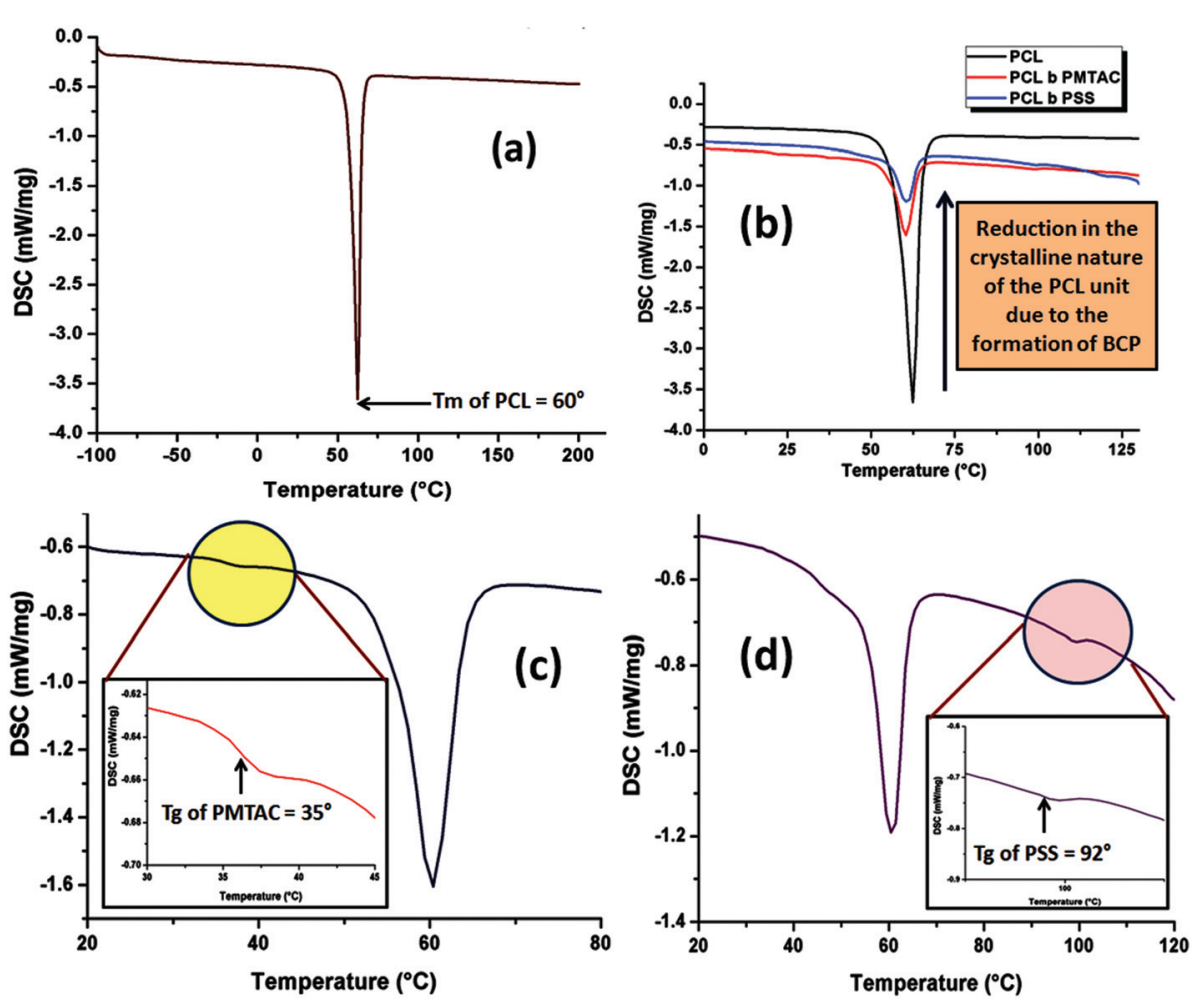

Fig. 6 DSC analysis of (a) PCL-OH, (b) reduction in intensity of the endotherm of PCL upon block copolymer formation, (c) PCL $70-b-P^{2} M_{A C} C_{88}$ and (d) $\mathrm{PCL}_{70}-b-\mathrm{PSS}_{48}$. 
(i)

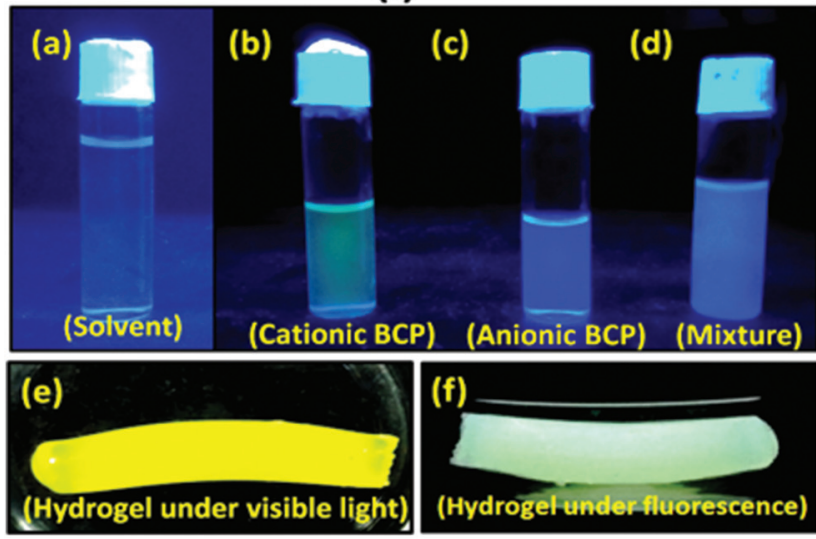

(ii)

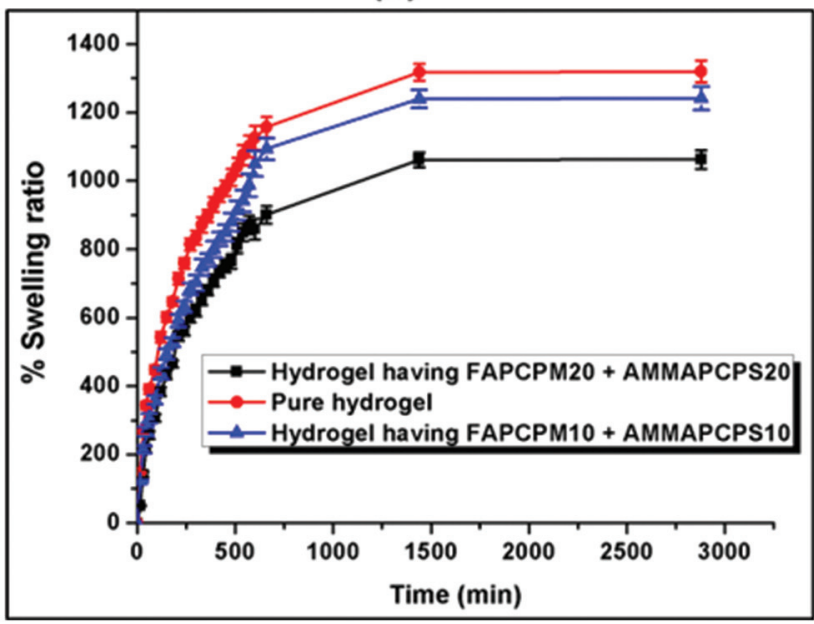

Fig. 7 (i) Fluorescence images of the (a) solvent (control), (b) $\mathrm{FAPCL}_{70}$ $b$-PMTAC 48 micelle, (c) AMMAPCL ${ }_{70}-b-\mathrm{PSS}_{48}$ micelle, (d) charge neutral mixture of $\mathrm{FAPCL}_{70}-b-\mathrm{PMTAC}_{48}$ and $A M M A P C L_{70}-b-\mathrm{PSS}_{48}$, (e) fluorescent hydrogel under visible light, (f) fluorescent hydrogel under a fluorescence lamp. (ii) \% Swelling ratio of the prepared hydrogel at $\mathrm{pH}=$ 7.4 .

result, the inter-crosslinking volume is high, which results in a higher extent of swelling.

\section{Mechanical analysis of the hydrogel}

As mentioned in the swelling experiment the incorporation of the ionic BCP generates ionic crosslinking inside the hydrogel, which results in a lower degree of swelling compared to the non-modified hydrogel sample. The formation of ionic crosslinking also has an effect on the transparency of the hydrogel. As shown in Fig. 8a the incorporation of BCPs reduces the transparency of the hydrogel, which provides support to the idea that the formation of ionic crosslinking inside the hydrogel affects transparency. The results obtained from the tensile study are summarized in Fig. 8 b.

The data showed that the incorporation of BCPs of a specific block length can provide a higher extent of elongation and modulus compared to the non-modified hydrogel sample. Incorporation of $\mathrm{FAPCL}_{70}-b-\mathrm{PMTAC}_{48}+\mathrm{AMMA} \mathrm{PCL}_{70}-b-\mathrm{PSS}_{48}$ into the hydrogel provides $(700 \pm 10) \%(p<0.05)$ elongation before breaking as compared to the non-modified hydrogel $((430 \pm 10) \%$ elongation before breaking). This might be due to the presence of elastic ionic interactions between the oppositely charged BCPs. ${ }^{47}$ Interestingly, it was observed that the hydrogel with FAPCL $_{70}-b-\mathrm{PMTAC}_{97}+\mathrm{AMMA} \mathrm{PCL}_{70}-b-\mathrm{PSS}_{97}$ showed a comparatively lower level of elongation (492 \pm 10$) \%$ $(p>0.05)$ before breaking, but showed a higher modulus. This result can be explained by considering the transparency result. From the image it is clearly observed that the presence of FAPCL $_{70}-b-$ PMTAC $_{97}+$ AMMA PCL70- $b-$ PSS $_{97}$ provides poor transparency, which means generation of higher ionic interaction between the BCPs, which leads to large ionic cluster formation. This provides greater stiffness to the $\mathrm{FAPCL}_{70}-b$ $\mathrm{PMTAC}_{97}+$ AMMA PCL $_{70}-b$ - $\mathrm{PS}_{97}$ hydrogel, as compared to the FAPCL $_{70}-b-\mathrm{PMTAC}_{48}+$ AMMA PCL $70-b-\mathrm{PSS}_{48}$ filled hydrogel. The tensile images of the sample are mentioned in Fig. 8c, which clearly makes sense about the extent of elongation of the prepared hydrogels.

\section{Study of the self-healing property of the hydrogel}

In our study we observed the self-healing ability of the BCP $\left(\right.$ FAPCL $_{70}-b-\mathrm{PMTAC}_{48}+$ AMMA $\left.\mathrm{PCL}_{70}-b-\mathrm{PSS}_{48}\right)$ incorporated hydrogel at $\mathrm{pH}=7.4$ (physiological $\mathrm{pH}$ ) by adopting the "scratch and heal" method. For this, we made a notch over the hydrogel surface having a depth of approximately $0.5 \mathrm{~mm}$ using a sharp knife. The image of the notched hydrogel sample is presented in Fig. 8d(i). After that a PBS buffer solution of $\mathrm{pH}=7.4$ was sprayed over it and kept for 30 minutes in that condition. After that, the image of the healed hydrogel sample was again obtained from an optical microscope and the image is presented in Fig. 8d(ii). Tensile testing of the healed hydrogel was performed to examine the retention of the mechanical properties of the hydrogel after healing. From the tensile testing results (Fig. 8e) it was observed that after being healed, the mechanical properties of the hydrogel were almost similar to those of the uncut hydrogel sample. The healed hydrogel showed (550 \pm 10$) \%$ elongation (tensile strength $=0.19 \pm 0.01 \mathrm{MPa})$, whereas the uncut hydrogel showed $(700 \pm 10) \%$ elongation before breaking $(0.32 \pm 0.01$ $\mathrm{MPa})$. The probable reason for the self-healing can be explained by considering the ionic interaction phenomenon. In this case the presence of the oppositely charged BCPs played a role in the self-healing process. When the buffer solution of $\mathrm{pH}=7.4$ was sprayed over the cut, the polymeric segments became swollen, resulting in close contact of the cationic (containing $-\mathrm{N}\left(\mathrm{CH}_{3}\right)_{3}{ }^{+}$) and the anionic (containing $-\mathrm{SO}_{3}{ }^{-}$) BCPs. Due to the formation of the elastic ionic interaction between the two segments of the hydrogel, after the cut, the hydrogel surface became healed.

DMA analysis. The ionic interaction induced self-healing in the fluorescent hydrogel system was further studied by creep and stress relaxation experiments.

Creep study. Creep or cold flow of the solid material describes the deformation of the material under a constant stress. The rate of deformation depends on the amount of 
(d)

(a)
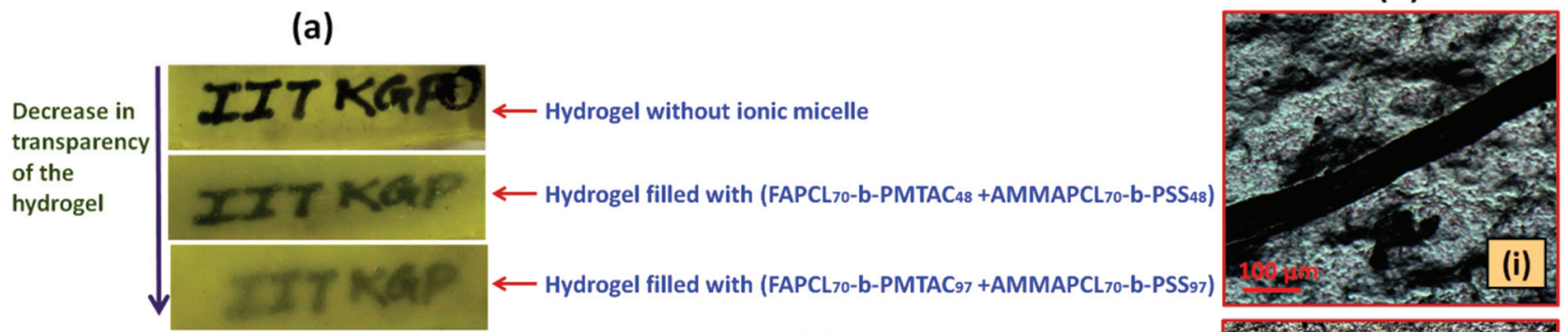

(c)
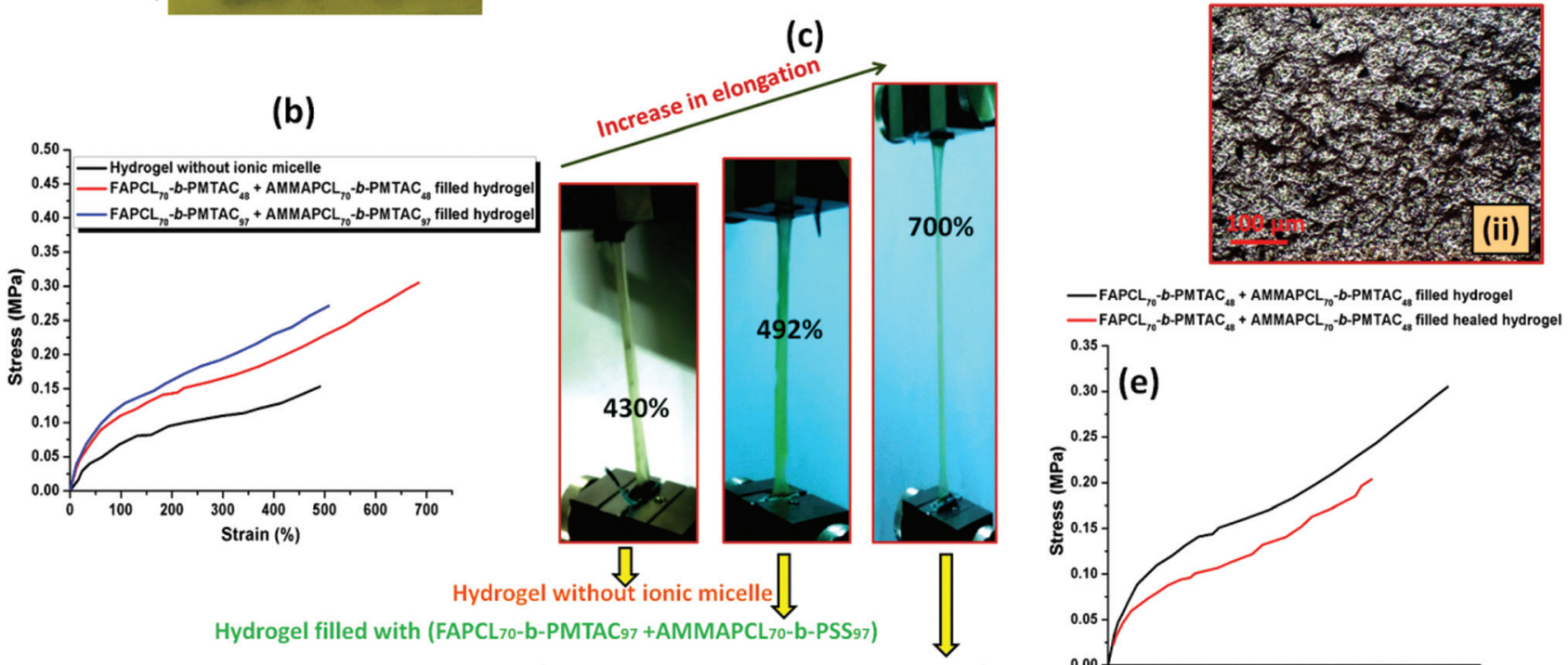

Hydrogel withoưt ionic micelle Hydrogel filled with (FAPCL70-b-PMTAC97 + AMMAPCL70-b-PSS97)

Hydrogel filled with (FAPCL70-b-PMTAC $48+$ AMMAPCL70-b-PSS 48 )
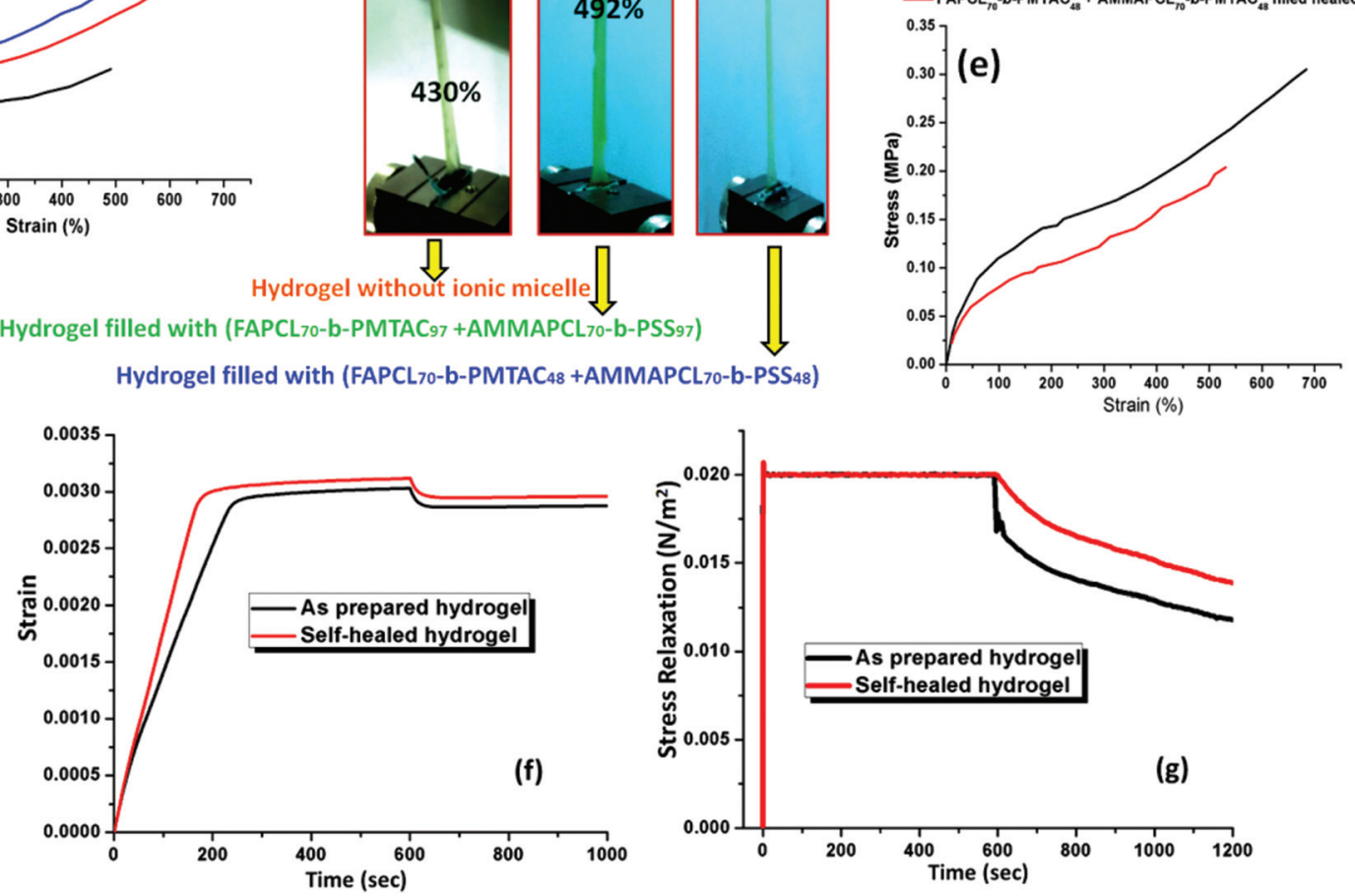

Fig. 8 (a) Variation of the transparency of the hydrogel upon incorporation of micelles of different block lengths, (b) tensile strength measurement, (c) a picture of the extent of elongation of hydrogels upon incorporation of micelles of different block lengths, (d) images of (i) notched and (ii) healed hydrogels, (e) a tensile test of the as prepared and healed hydrogels, (f) a comparative creep study of the hydrogels under a constant stress of $0.1 \mathrm{MPa}$ at $25^{\circ} \mathrm{C},(\mathrm{g})$ a comparative stress relaxation study of the hydrogels under a constant strain of $0.02 \%$ at $25^{\circ} \mathrm{C}$.

applied load and exposure time of the load. Creep in the hydrogel occurs due to its viscoelastic nature. In our case both the as prepared ionic hydrogel and the self-healed hydrogel were subjected to a step constant stress of $0.1 \mathrm{MPa}$ and the corresponding viscoelastic creep of the hydrogel was recorded. The response from the hydrogel (stress-strain curve) was modelled using the Kelvin-Voigt model as ${ }^{48}$

$$
J(t)=J_{0}+\sum_{i=1}^{n} J_{i}\left[1-e^{-t / \tau_{i}}\right]
$$

where $J(t)$ and $J_{0}$ are the creep compliance after time $t$ and instant compliance, respectively. $J_{0}$ and $\tau_{i}$ are constant. From Fig. 8f, it was observed that compared to the as prepared hydrogel, the self-healed hydrogel responded faster to the applied stress. From the obtained result it can be said that due to the consecutive cut and healing process, an obvious loss of covalent bond (crosslinking by MBA) occurred in case of the self-healed hydrogel. As a result, a large amount of primary creep or transient creep was observed in the case of the selfhealed hydrogel as compared to the as prepared hydrogel. It 
was observed that the rate of achieving the secondary creep or "steady-state-creep" was higher in the case of the self-healed gel as compared to the as prepared hydrogel. The data thus indicate that the only factor that resists the applied stress was the ionic interaction which acted between the ionic BCP micelles inside the hydrogel. This indeed supports the concept of ionic interactions as the main driver of self-healing. ${ }^{49}$ In contrast, in the as prepared hydrogel, due to the presence of both covalent bonds and ionic interactions, resistance against the applied stress was high. As a result, achievement of the secondary creep stage was delayed. Although both hydrogels showed a comparable creep compliance value (Fig. S6†), it was observed that both hydrogels had not experienced any tertiary stage creep in the presence of $0.1 \mathrm{MPa}$ stress for a time period of 1200 s. An immediate drop in strain was observed after the withdrawal of the stress. As a result, a gradual recovery of the residual strain was witnessed. The extent of the immediate drop in strain was slightly increased in the case of the as prepared hydrogel compared to the self-healed hydrogel and this difference was ascribed to the synergistic contribution of both the covalent crosslinks and ionic crosslinks towards the elasticity.

Stress relaxation study. Stress relaxation can be explained as the decrease in stress under constant strain conditions. In our hydrogel system, both the hydrogels (as prepared and selfhealed) passed through a constant strain of $0.02 \%$ at $25{ }^{\circ} \mathrm{C}$. From Fig. $8 \mathrm{~g}$, it can be observed that the rate of relaxation of stress was faster in the case of the as prepared hydrogel compared to the self-healed one. Maxwell modelled the stress relaxation as

$$
E(t)=\sum_{i=1}^{n} E_{i} e^{-t / \tau_{i}}
$$

where $E(t)$ is the relaxation modulus at time $(t)$ and $E_{i}$ and $\tau_{i}$ are constants. SAs observed in the creep experiment from the stress relaxation curve (stress-time curve) showed that the response of the as prepared hydrogel was rapid compared to the self-healed hydrogel (relaxation of stress) after removal of the applied strain. This again proves the higher elasticity of the as prepared hydrogel due to the combined effect of covalent crosslinks and ionic interactions. ${ }^{50}$ In contrast, in the case of self-healed gel the relaxation only occurred due to the presence of ionic interaction, which also supports the concept of ionic interaction based healing.

In vitro cell cytotoxicity assay. An in vitro cell viability study was carried out to determine the cell cytotoxicity of the synthesized hydrogel. Charged polymers in solution or as block copolymers in micellar dispersion are often toxic if they are allowed to disrupt cell membranes. To estimate the cell cytotoxicity of the prepared hydrogel a MTT colorimetric assay test was carried out using NIH 3T3 fibroblast cells as the test cell line. From Fig. 9 it was observed that the hydrogels containing BCPs of different ionic block lengths showed good cell proliferation compared to the control sample. It is reported that the cell proliferation in some way depends on the surface hydrophilicity and the micro roughness of the surface. ${ }^{51}$ As shown

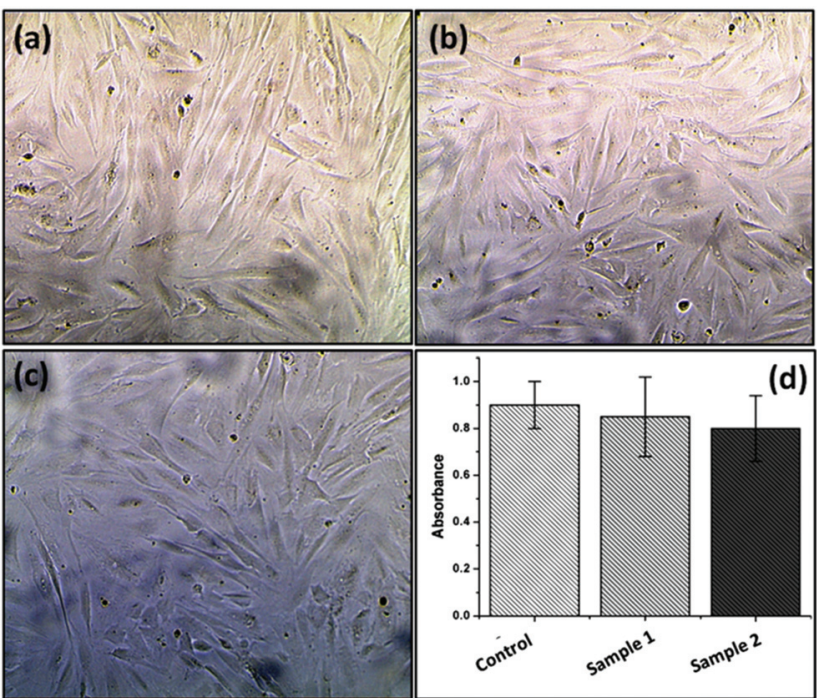

Fig. 9 In vitro cell cytotoxicity assay of (a) the control sample (only polyacrylamide hydrogel), (b) the $\mathrm{FAPCL}_{70}-b-\mathrm{PMTAC}_{48}+\mathrm{AMMA} \mathrm{PCL}_{70^{-}}$ $b-\mathrm{PSS}_{48}$ filled hydrogel and (c) the $\mathrm{FAPCL}_{70}-b-\mathrm{PMTAC}_{97}+\mathrm{AMMA} \mathrm{PCL}_{70^{-}}$ $b-\mathrm{PSS}_{97}$ filled hydrogel against NIH $3 \mathrm{T3}$ fibroblast cells and (d) the respective absorbance values.

in Fig. S5(b) $\dagger$ on formation of ionic BCPs the WCA value reduced from $78^{\circ}$ (homo PCL) to $32^{\circ}$ for the cationic BCP and $36^{\circ}$ for the anionic BCP. Furthermore, on mixing the two ionic BCPs at an almost equal charge ratio the WCA value of decreased to $20^{\circ}$ and a rough surface was created, as shown in FESEM and AFM analysis. Both of these factors and the charge state of the hydrogel are expected to provide a surface that is favourable for cell proliferation. The extent of cytotoxicity can be measured by measuring the O.D. value of the formed purple formazan salt at $590 \mathrm{~nm}$. The absorbance result of the cytotoxicity assay is summarized in Fig. 9d. A Student's $t$-test was carried out to compare the statistical significance of the test samples (a hydrogel with $\mathrm{FAPCL}_{70}-b-\mathrm{PMTAC}_{48}+$ AMMA $\mathrm{PCL}_{70}-b-\mathrm{PSS}_{48}$ (Sample 1) and $\mathrm{FAPCL}_{70}-b-\mathrm{PMTAC}_{97}+$ AMMA $\mathrm{PCL}_{70}-b$ - $\mathrm{PSS}_{97}$ (Sample 2)) against the control (only polyacrylamide hydrogel) and it was found that $p>0.05$, which signifies that there is no significant difference in cell proliferation between the test sample and the control one. So it can be concluded that in the presence of the test sample there was no cell death. This indicates that the prepared hydrogels are non-toxic in nature as compared to a conventional polyacrylamide gel.

\section{Conclusions}

PCL based fluorescently labelled cationic (FA tagged) and anionic (AMMA tagged) block copolymers were successfully prepared using consecutive ROP of $\varepsilon$-caprolactone and xanthate mediated RAFT polymerization. The BCPs are able to form micelles in a $1: 4$ (volume ratio) DMF : water mixture with core shell morphologies. The formed morphology was evaluated by using FESEM, HRTEM and AFM analyses. The size dis- 
tribution and hydrodynamic diameter of the formed micelle were determined using DLS analysis. Water contact angle analysis also supports the formation of BCPs by showing a reduced water contact angle value as compared to PCL. After that, the oppositely charged BCPs were incorporated into a poly(acrylamide) based hydrogel. Importantly, this material showed fluorescence emission under visible light and fluorescent light. Along with the fluorescence phenomenon the modified hydrogel was able to self-heal at $\mathrm{pH}=7.4$. MTT assay experiment revealed that the synthesized fluorescence active hydrogels are non-toxic in nature. This type of fluorescence active self-healable, mechanically strong and non-toxic hydrogel may be a potentially smart material in the field of tissue engineering and sensing applications in the near future.

\section{Conflicts of interest}

There are no conflicts to declare.

\section{Acknowledgements}

Funding for Mr Sovan Lal Banerjee's fellowship was kindly provided by the IIT Kharagpur. MRC (MR/N501888/2) for funding to allow Banerjee to visit and research at University of Bradford and for providing post-doctoral fellowship for Hoskins.

\section{Notes and references}

1 O. Wichterle and D. Lim, Hydrophilic Gels for Biological Use, Nature, 1960, 185(4706), 117-118.

2 K. Y. Lee and D. J. Mooney, Hydrogels for Tissue Engineering, Chem. Rev., 2001, 101(7), 1869-1880.

3 H. Dai, Q. Chen, H. Qin, Y. Guan, D. Shen, Y. Hua, Y. Tang and J. Xu, A Temperature-Responsive Copolymer Hydrogel in Controlled Drug Delivery, Macromolecules, 2006, 39(19), 6584-6589.

4 Y. Luo and M. S. Shoichet, A Photolabile Hydrogel for Guided Three-Dimensional Cell Growth and Migration, Nat. Mater., 2004, 3(4), 249.

5 A. Hasan, A. Paul, N. E. Vrana, X. Zhao, A. Memic, Y.-S. Hwang, M. R. Dokmeci and A. Khademhosseini, Microfluidic Techniques for Development of 3D Vascularized Tissue, Biomaterials, 2014, 35(26), 7308-7325.

6 S. J. Song, J. Choi, Y. D. Park, J. J. Lee, S. Y. Hong and K. Sun, A Three-Dimensional Bioprinting System for Use With a Hydrogel-Based Biomaterial and Printing Parameter Characterization, Artif. Organs, 2010, 34(11), 1044-1048.

7 A. S. Hoffman, Hydrogels for biomedical applications, Adv. Drug Delivery Rev., 2012, 64, 18-23.

8 X. Zhang, C. L. Pint, M. H. Lee, B. E. Schubert, A. Jamshidi, K. Takei, H. Ko, A. Gillies, R. Bardhan and J. J. Urban, Optically-and thermally-responsive Programmable Materials based on Carbon Nanotube-hydrogel Polymer Composites, Nano Lett., 2011, 11(8), 3239-3244.
9 Y. J. Heo, H. Shibata, T. Okitsu, T. Kawanishi and S. Takeuchi, Long-term in vivo Glucose Monitoring using Fluorescent Hydrogel Fibers, Proc. Natl. Acad. Sci. U. S. A., 2011, 108(33), 13399-13403.

10 J. T. Suri, D. B. Cordes, F. E. Cappuccio, R. A. Wessling and B. Singaram, Continuous glucose sensing with a fluorescent thin-film hydrogel, Angew. Chem., Int. Ed., 2003, 42(47), 5857-5859.

11 Y. Gong, M. Gao, D. Wang and H. Möhwald, Incorporating Fluorescent CdTe Nanocrystals into a Hydrogel via Hydrogen Bonding: Toward Fluorescent Microspheres with Temperature-responsive Properties, Chem. Mater., 2005, 17(10), 2648-2653.

12 B. HyeanáKim, An insulin-sensing sugar-based fluorescent hydrogel, Chem. Commun., 2006, (17), 1842-1844.

13 N. Artzi, N. Oliva, C. Puron, S. Shitreet, S. Artzi, A. Bon Ramos, A. Groothuis, G. Sahagian and E. R. Edelman, In Vivo and in Vitro Tracking of Erosion in Biodegradable materials Using non-invasive Fluorescence Imaging, Nat. Mater., 2011, 10(9), 704.

14 W. Wang, J. Liu, C. Li, J. Zhang, J. Liu, A. Dong and D. Kong, Real-time and Non-invasive Fluorescence Tracking of In Vivo Degradation of the Thermosensitive PEGlyated Polyester Hydrogel, J. Mater. Chem. B, 2014, 2(26), 4185-4192.

15 Y. Dong, G. Jin, C. Ji, R. He, M. Lin, X. Zhao, A. Li, T. J. Lu and $\mathrm{F}$. Xu, Non-invasive tracking of Hydrogel Degradation Using Upconversion Nanoparticles, Acta Biomater., 2017, 55, 410-419.

16 T. V. Shkand, M. O. Chizh, I. V. Sleta, B. P. Sandomirsky, A. L. Tatarets and L. D. Patsenker, Assessment of Alginate Hydrogel Degradation in Biological Tissue Using Viscositysensitive Fluorescent Dyes, Methods Appl. Fluoresc., 2016, 4(4), 044002.

17 X. Ma, X. Sun, D. Hargrove, J. Chen, D. Song, Q. Dong, X. Lu, T.-H. Fan, Y. Fu and Y. Lei, A Biocompatible and Biodegradable Protein Hydrogel with Green and Red Autofluorescence: preparation, Characterization and In vivo Biodegradation Tracking and Modeling, Sci. Rep., 2016, 6.

18 T. Mako and M. Levine, Synthesis of a Fluorescent Conjugated Polymer in the Undergraduate Organic Teaching Laboratory, J. Chem. Educ., 2013, 90(10), 1376-1379.

19 A. S. Ribeiro and R. J. Mortimer, Conjugated Conducting Polymers with Electrochromic and Fluorescent Properties. In Electrochemistry, 2015, pp. 21-49.

20 O. G. Tovmachenko, C. Graf, D. J. van den Heuvel, A. van Blaaderen and H. C. Gerritsen, Fluorescence Enhancement by Metal-core/silica-shell Nanoparticles, Adv. Mater., 2006, 18(1), 91-95.

21 J. Liu and R. H. Hurt, Ion Release Kinetics and Particle Persistence in Aqueous Nano-silver Colloids, Environ. Sci. Technol., 2010, 44(6), 2169-2175.

22 X. Zhang, S. Wang, L. Xu, L. Feng, Y. Ji, L. Tao and Y. Wei, Biocompatible polydopamine fluorescent organic nanoparticles: facile preparation and cell imaging, Nanoscale, 2012, 4(18), 5581-5584. 
23 A. H. Loo, Z. Sofer, D. Bouša, P. Ulbrich, A. Bonanni and M. Pumera, Carboxylic Carbon Quantum Dots as a Fluorescent Sensing Platform for DNA Detection, ACS Appl. Mater. Interfaces, 2016, 8(3), 1951-1957.

24 D. Chowdhury, N. Gogoi and G. Majumdar, Fluorescent carbon dots obtained from chitosan gel, RSC Adv., 2012, 2(32), 12156-12159.

25 A. Cayuela, M. L. Soriano, S. R. Kennedy, J. Steed and M. Valcárcel, Fluorescent Carbon Quantum Dot Hydrogels for Direct Determination of Silver Ions, Talanta, 2016, 151, 100-105.

26 A. A. Neyfakh, Use of Fluorescent Dyes as Molecular Probes for the Study of Multidrug Resistance, Exp. Cell Res., 1988, 174(1), 168-176.

27 X. Zhang, K. Wang, M. Liu, X. Zhang, L. Tao, Y. Chen and Y. Wei, Polymeric AIE-based nanoprobes for biomedical applications: recent advances and perspectives, Nanoscale, 2015, 7(27), 11486-11508.

28 T. Swift, L. Swanson, M. Geoghegan and S. Rimmer, The pH-responsive Behaviour of Poly(acrylic acid) in Aqueous Solution is Dependent on Molar Mass, Soft Matter, 2016, 12(9), 2542-2549.

29 L. Ruiz-Pérez, A. Pryke, M. Sommer, G. Battaglia, I. Soutar, L. Swanson and M. Geoghegan, Conformation of Poly (methacrylic acid) Chains in Dilute Aqueous Solution, Macromolecules, 2008, 41(6), 2203-2211.

30 T. Swift, L. Swanson and S. Rimmer, Poly(acrylic acid) Interpolymer Complexation: use of a Fluorescence Time Resolved Anisotropy as a Poly(acrylamide) Probe, RSC Adv., 2014, 4(101), 57991-57995.

31 J. J. Heyward and K. P. Ghiggino, Fluorescence Polarization study of the poly(acrylic acid)/poly(ethylene oxide) Interpolymer Complex in Aqueous Solution, Macromolecules, 1989, 22(3), 1159-1165.

32 T. Swift, J. Lapworth, K. Swindells, L. Swanson and S. Rimmer, $\mathrm{pH}$ Responsive Highly Branched poly(N-isopropylacrylamide) with Trihistidine or Acid Chain Ends, RSC Adv. , 2016, 6(75), 71345-71350.

33 T. Swift, N. Paul, L. Swanson, M. Katsikogianni and S. Rimmer, Förster Resonance Energy Transfer Across Interpolymer Complexes of Poly(acrylic acid) and Poly(acrylamide), Polymer, 2017, 123, 10-20.

34 S. L. Banerjee, M. Khamrai, P. Kundu and N. K. Singha, Synthesis of a Self-healable and $\mathrm{pH}$ Responsive Hydrogel Based on an Ionic Polymer/clay Nanocomposite, RSC Adv., 2016, 6(85), 81654-81665.

35 D. Habault, H. Zhang and Y. Zhao, Light-triggered Selfhealing and Shape-memory Polymers, Chem. Soc. Rev., 2013, 42(17), 7244-7256.

36 Y.-L. Liu and T.-W. Chuo, Self-healing polymers based on thermally reversible Diels-Alder chemistry, Polym. Chem., 2013, 4(7), 2194-2205.

37 H. Gao, N. Wang, X. Hu, W. Nan, Y. Han and W. Liu, Double Hydrogen-Bonding pH-Sensitive Hydrogels Retaining High-Strengths Over a Wide pH Range, Macromol. Rapid Commun., 2013, 34(1), 63-68.
38 C. Li and G. Shi, Functional gels based on chemically modified graphenes, Adv. Mater., 2014, 26(24), 3992-4012.

39 J. A. Foster, R. M. Parker, A. M. Belenguer, N. Kishi, S. Sutton, C. Abell and J. R. Nitschke, Differentially addressable cavities within metal-organic cage-cross-linked polymeric hydrogels, J. Am. Chem. Soc., 2015, 137(30), 97229729.

40 S. W. Kuo, C. F. Huang, C. H. Lu, H. M. Lin, K. U. Jeong and F. C. Chang, Syntheses and Specific Interactions of Poly ( $\varepsilon$-caprolactone)-block-poly (vinyl phenol) Copolymers Obtained via a Combination of Ring-Opening and AtomTransfer Radical Polymerizations, Macromol. Chem. Phys, 2006, 207(21).

41 V. K. Patel, A. K. Mishra, N. K. Vishwakarma, C. S. Biswas and B. Ray, (S)-2-(Ethyl propionate)-(O-ethyl xanthate) and (S)-2-(Ethyl isobutyrate)-(O-ethyl xanthate)-mediated RAFT polymerization of N-vinylpyrrolidone, Polym. Bull., 2010, 65(2), 97-110.

42 T. Swift, R. Hoskins, R. Telford, R. Plenderleith, D. Pownall and S. Rimmer, Analysis Using Size Exclusion Chromatography of poly(N-isopropyl acrylamide) using Methanol as an Eluent, J. Chromatogr., A, 2017, 1508, 15-23.

43 K. K. Gupta, A. Kundan, P. K. Mishra, P. Srivastava, S. Mohanty, N. K. Singh, A. Mishra and P. Maiti, Polycaprolactone composites with TiO 2 for potential nanobiomaterials: tunable properties using different phases, Phys. Chem. Chem. Phys., 2012, 14(37), 12844-12853.

44 S. C. Owen, D. P. Chan and M. S. Shoichet, Polymeric Micelle Stability, Nano Today, 2012, 7(1), 53-65.

45 G. Riess, Micellization of Block Copolymers, Prog. Polym. Sci., 2003, 28(7), 1107-1170.

46 S. Zhai, Y. Ma, Y. Chen, D. Li, J. Cao, Y. Liu, M. Cai, X. Xie, Y. Chen and X. Luo, Synthesis of an Amphiphilic Block Copolymer Containing Zwitterionic Sulfobetaine as a Novel pH-sensitive Drug Carrier, Polym. Chem., 2014, 5(4), 12851297.

47 T. L. Sun, T. Kurokawa, S. Kuroda, A. B. Ihsan, T. Akasaki, K. Sato, M. A. Haque, T. Nakajima and J. P. Gong, Physical hydrogels Composed of Polyampholytes Demonstrate High Toughness and Viscoelasticity, Nat. Mater., 2013, 12(10), 932-937.

48 M. T. Shaw and W. J. MacKnight, Introduction to Polymer Viscoelasticity, John Wiley \& Sons, Inc., Hoboken, New Jersey, 3rd edn, 2005, ch. 2, p. 51.

49 S. N. Karobi, T. L. Sun, T. Kurokawa, F. Luo, T. Nakajima, T. Nonoyama and J. P. Gong, Creep Behavior and Delayed Fracture of Tough Polyampholyte Hydrogels by Tensile Test, Macromolecules, 2016, 49(15), 5630-5636.

50 X. Zhao, N. Huebsch, D. J. Mooney and Z. Suo, Stress-relaxation behavior in gels with ionic and covalent crosslinks, J. Appl. Phys., 2010, 107(6), 063509.

51 S. Yuan, G. Xiong, X. Wang, S. Zhang and C. Choong, Surface modification of polycaprolactone substrates using collagen-conjugated poly (methacrylic acid) brushes for the regulation of cell proliferation and endothelialisation, J. Mater. Chem., 2012, 22(26), 13039-13049. 